\title{
Comparison Analysis Between Simulation and Experiment of Cutting Force and Cutting Stress as Well as Chip Morphology During the Macro and Nano Cutting of Single Crystal Copper
}

Dongju Chen ( $\nabla$ djchen@bjut.edu.cn )

Beijing University of Technology

Shuiyuan Wu

Beijing University of Technology

Yazhong He

Beijing University of Technology

Shupei Li

Beijing University of Technology

Yuchi Luo

China Academy of Engineering Physics, Mianyang

Xiang Wang

Jingdezhen Ceramic institute, Jingdezhen

\section{Research Article}

Keywords: macro and nano, cutting, finite element, molecular dynamics, experiment

Posted Date: September 7th, 2021

DOl: https://doi.org/10.21203/rs.3.rs-849526/v1

License: (c) (1) This work is licensed under a Creative Commons Attribution 4.0 International License.

Read Full License 


\title{
Comparison analysis between simulation and experiment of cutting force and cutting stress as well as chip morphology during the macro and nano cutting of single crystal copper
}

\author{
Chen Dongju ${ }^{1}$, Wu Shuiyuan ${ }^{1}$, He Yazhong ${ }^{1}$, Li Shupei $^{1}$, Luo Yuchi ${ }^{2}$, Wang Xiang ${ }^{3}$ \\ 1. Faculty of Materials and Manufacturing, Beijing University of Technology, Beijing, 100020 \\ 2. Institute of Nuclear Physics and Chemistry, China Academy of Engineering Physics, Mianyang, \\ Sichuan, 621000 \\ 3. Jingdezhen Ceramic institute, Jingdezhen, Jiangxi, 333000 \\ Corresponding author: Chen Dongju \\ Email:djchen@bjut.edu.cn
}

\begin{abstract}
In this paper, the simulation and experiment comparison of cutting force, cutting stress and chip morphology during the macro and nano cutting of single crystal copper are carried out. Firstly, a finite element method based on Johnson-Cook metal strength and failure model were used to establish a macro cutting model, and the cutting force, cutting stress, cutting displacement and chip morphology were obtained. Then a molecular dynamics simulation was used to establish a nano cutting model, and the cutting force, von mises stress and chip morphology were obtained. Afterwards, a comparative analysis of the two was carried out. Finally, the external turning experiment was used to verify the simulation results of the macro cutting model. The results show that: 1 . The change trend of the cutting force in $\mathrm{x}$ and $\mathrm{y}$ directions are different,but the corresponding ratios of cutting forces in $\mathrm{x}$ and $\mathrm{y}$ directions in macro and nano cutting process are very close, and the corresponding ratios of the average macro and nano cutting forces in $\mathrm{x}$ and $\mathrm{y}$ directions are also very close. 2. The cutting stress in nano cutting process was about 100 times of macro cutting stress. 3. The chip length in macro cutting process is larger than the chip length in nano cutting process, and the shape is more regular. 4 . The experimental cutting force change trend is very similar to the simulation cutting force change trend, but there exits difference in the value between the experiment cutting forces and simulated cutting forces.
\end{abstract}

Keywords: macro and nano, cutting, finite element, molecular dynamics, experiment

\section{Introduction}

In the metal cutting process, the workpiece is subjected to a strong shear force to form chips, and separated from the workpiece. Therefore, an accurate description of the plastic deformation process and separation process of metal in the cutting process is an important step to explain the metal cutting mechanism. Commonly described metal plastic constitutive models in the metal cutting process include bilinear isotropic hardening model, multiple linear isotropic hardening model and Johnson cook plastic constitutive model. Among them, the Johnson cook plastic constitutive model can better describe the large deformation behavior in the metal cutting process, and give the relationship between metal stress and strain at the same time, and the simulation results are in good agreement with the experimental results. As for the separation behavior of chips and workpieces in the metal cutting process, it is a metal failure behavior in itself. Therefore, a reasonable description of metal failure behavior is of great significance for describing the separation of chips and workpieces during the cutting process. The common method is to use failure models for description, 
such as shear failure, principal stress failure, principal strain failure and Johnson cook failure criteria. Among them, the Johnson cook failure criterion is more reasonable for describing metal failure behavior during metal cutting. Johnson and Cook [1] studied the stress-strain relationship and failure characteristics of three materials: copper, iron and steel during large deformation. Through the implementation of the torque test, the Hopkinson pressure bar test and the quasi-static tensile test on the above three materials, and the analysis of the results, a flow stress model including strain rate, temperature and pressure is introduced, which can perform better describing the relationship between stress and strain of metal under large deformation, high strain rate and high temperature. At the same time, a metal failure model is introduced, which achieves metal failure when a variable value reaches 1. Zhou [3] verified the effectiveness of Johnson Cook constitutive model and failure model by performing stress and strain tests on different metals. Sahu [4] established a finite element model of aluminum alloy using Johnson Cook model, and simulated it, and obtained the relationship between stress and strain of aluminum alloy in large deformation. Liu [5] used the Johnson Cook model and the Power Law model to compare the flow stress changes of oxygen-free copper during large plastic deformation, and found that the prediction results of the Johnson Cook model are more consistent with the experimental results. Palanisamy [6] established a cutting force model for end milling, and conducted experimental verification at different cutting depths, and found that the results were in good agreement. At the same time, the tool and chip interface temperature under different processing conditions were theoretically analyzed to study the effect of heat on cutting force, and the experiment was used to verify the theoretical cutting temperature, so as to provide a reference for limiting the effect of cutting temperature on cutting force. Wang [7] used an algorithm that considers tool geometry, vibration effects, cutting speed changes, and friction between the tool and chips to calculate the cutting force during the end milling process, and compared it with the experiment, and found that the results are basically consistent. Zhai [8] studied the finite element method to simulate the process of PCBN cutting of nickel-based superalloy GH4169, and combined with experimental comparison and verification. Finally, the changing laws of cutting temperature and cutting force under different cutting parameters are obtained, which provides a reference for the efficient processing of GH4169 superalloy with PCBN tools. Dai [16] used molecular dynamics simulation methods to study the nano-cutting process of ultra-precision elliptical vibration assisted cutting (UEVAC) on single crystal silicon, and studied the effects of different vibration frequencies, amplitude ratios and phase differences on cutting force, cutting stress and cutting heat. Chen [17] used molecular dynamics to simulate the surface and sub-surface deformation mechanism of gallium arsenide in the nano-cutting process, and at the same time studied the influence of crystal anisotropy on the type and density of dislocations through different models. In this paper, Johnson Cook constitutive model and failure model are used to describe the stress-strain relationship and failure relationship in the metal cutting process, thereby establishing a finite element model of cemented carbide cutting single crystal copper, and obtaining the cutting force, vonmises equivalent stress, and cutting displacement during the cutting process. And chip morphology as well as the cutting mechanism in the cutting process were analyzed at the same time. Then the molecular dynamics simulation method was used to establish a molecular dynamics model of diamond cutting single crystal copper, and the size of each part of the macro and nano scale model was kept in a certain proportion. Through molecular dynamics simulation, the cutting force, cutting stress and chip morphology in the nano-cutting process were obtained, and the results were compared and studied with the finite element simulation results. Finally, a cutting experiment of cemented carbide 
cutting single crystal copper was implemented, and the chip morphology and cutting force during the cutting process were obtained, and compared with the simulation results to verify the rationality and effectiveness of the simulation model, and at the same time analyzed the difference between the two. The difference provides a strong proof for the study of the cutting mechanism, cutting characteristics and cutting performance differences in the process of macro and nano scale diamond cutting of single crystal copper.

\section{Cutting model and cutting force}

The metal cutting model is shown in Fig.1. In the figure, the rake angle of the tool is denoted as $\alpha$, the back angle is denoted as $\beta$, the radius of the tool arc is $R$, the cutting depth of the tool is $D$, and the cutting force is respectively $F_{x}, F_{y}, F_{z}$. In the metal cutting process, part of the metal is subjected to the huge shear force of the tool to produce large plastic deformation, and finally form chips. Therefore, a reasonable description of the plastic deformation behavior of some metals is an important step to establish a metal cutting model. For this kind of large plastic deformation behavior, the Johnson Cook constitutive model can be used to describe. The Johnson Cook constitutive model is:

$\sigma_{e q}=\left(A+B \varepsilon_{p}^{n}\right)(1+C \ln \underset{p}{\stackrel{*}{*}})\left(1-T^{* m}\right)$

$\underset{p}{\&}=\& / \&$

$T^{*}=\left(T-T_{r}\right) /\left(T_{m}-T_{r}\right)$

Where $\sigma_{e q}$ is the equivalent plastic stress, $A, B, n, C, m$ is the material constant, $\varepsilon_{p}$ is the equivalent plastic strain, $\underset{p}{\mathbb{k}}$ is the relative equivalent plastic strain rate, $\underset{p}{\&}$ is the equivalent plastic strain rate, \& is the quasi-static strain rate, $T^{*}$ is the approximate specific temperature, $T$ is the real-time temperature, and $T_{r}$ is the room temperature, $T_{m}$ is the melting point temperature. For single crystal copper materials, the Johnson Cook constitutive model parameters can refer to hightemperature oxygen-free copper materials. The Johnson Cook model parameters are set as follows.

Table 1 Johnson Cook constitutive model parameters of single crystal copper

\begin{tabular}{ll}
\hline Variable & Value $(\mathrm{mm} / \mathrm{t} / \mathrm{s} / \mathrm{K})$ \\
\hline Initial yield stress A & $89.63 \mathrm{Mpa}$ \\
Hardening constant B & $291.64 \mathrm{Mpa}$ \\
Hardening exponent $\mathrm{n}$ & 0.31 \\
Strain Rate constant C & 0.025 \\
Thermal softening exponent $\mathrm{m}$ & 1.09 \\
\hline
\end{tabular}

In Table 1, the Johnson Cook material constants are respectively denoted as initial yield stress, hardening constant, hardening exponent, strain rate constant and thermal softening exponent. 


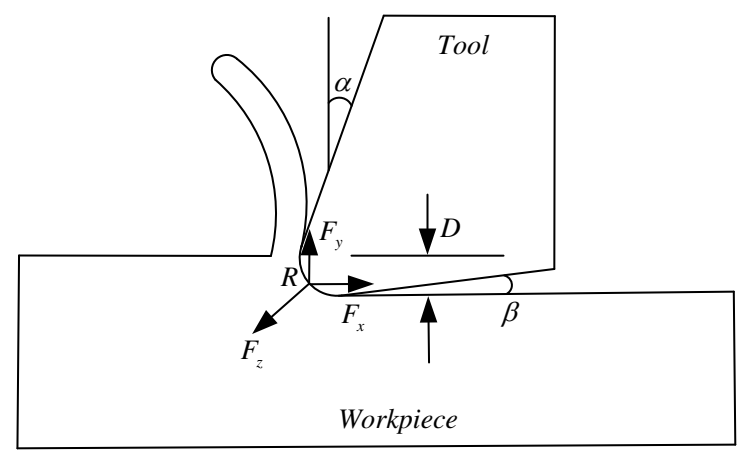

Fig.1 Metal cutting model

In the metal cutting process, part of the metal is subjected to huge shearing force and undergoes large plastic deformation, and finally separates from the original metal. From the point of view of material mechanics, this is a kind of shear failure behavior. For this kind of high strain rate and large deformation shear failure behavior, it is very important to describe the failure characteristics reasonably and construct the failure model. The Johnson Cook model can describe this shear failure behavior well, so it is widely used in metal cutting simulation. The Johnson Cook failure model is:

$D=\sum \frac{\Delta \varepsilon_{p}}{\varepsilon_{f}}$

Among them, $D$ is the failure constant of Johnson Cook failure model, and the material fails at that time $D=1 . \Delta \varepsilon_{p}$ is the equivalent plastic strain increment and $\varepsilon_{f}$ is the product term of stress, strain and temperature. And the expression of $\varepsilon_{f}$ is shown in formula (5).

$\varepsilon_{f}=\left[D_{1}+D_{2} \exp \left(D_{3} \eta\right)\right]\left(1+D_{4} \ln \underset{p}{\stackrel{*}{*}}\right)\left(1+D_{5} T^{*}\right)$

$\eta=\sigma_{H} / \sigma_{e q}$

Among them, $\varepsilon_{f}$ is the product term of stress, strain and temperature, $D_{1}, D_{2}, D_{3}, D_{4}, D_{5}$ are the material constant, $\sigma_{H}$ is the hydrostatic pressure, and $\sigma_{e q}$ is the equivalent stress.

The parameter settings of Johnson Cook failure model are shown in Table 2.

Table 2 Johnson Cook failure model parameters of single crystal copper

\begin{tabular}{lll}
\hline Variable & & Value $(\mathrm{mm} / \mathrm{t} / \mathrm{s} / \mathrm{K})$ \\
\hline Damage constant & $D_{1}$ & 0.54 \\
Damage constant & $D_{2}$ & 4.89 \\
Damage constant & $D_{3}$ & -3.03 \\
Damage constant & $D_{4}$ & 0.014 \\
Damage constant & $D_{5}$ & 1.12 \\
Melting temperature & 1356 \\
\hline
\end{tabular}

After the metal material strength model and failure model are established, the metal cutting 
simulation model can be established.

\section{Establishment of macro cutting model of single crystal copper}

The simulation model of diamond cutting single crystal copper is established by finite element method. The finite element method is based on the basic theory of finite element. This method divides the structure into several elements, and obtains the nodal force matrix of each element by distributing the overall force on each element node, and then combines the element stiffness matrix, and finally form the overall nodal force matrix and stiffness matrix. Then the elastic Hooke law is used to solve the displacement, and the strain is obtained through the relationship between strain and displacement, and finally the stress is solved through the stress strain constitutive relationship. Generally speaking, the overall nodal force matrix, stiffness matrix and nodal displacement matrix are expressed by the following equations:

$[F]=[K][d]$

Where $F$ is the nodal force matrix, $K$ is the stiffness matrix, and $d$ is the nodal displacement matrix. The specific matrix form is shown in formula (8).

$\left[\begin{array}{c}F_{1 x} \\ F_{1 y} \\ \mathrm{M} \\ F_{n z}\end{array}\right]=\left[\begin{array}{cccc}K_{11} & K_{12} & \mathrm{~L} & K_{1 n} \\ K_{21} & K_{22} & \mathrm{~L} & K_{2 n} \\ \mathrm{M} & \mathrm{M} & \mathrm{O} & \mathrm{M} \\ K_{n 1} & K_{n 2} & \mathrm{~L} & K_{n z}\end{array}\right]\left[\begin{array}{c}d_{1 x} \\ d_{1 y} \\ \mathrm{M} \\ d_{n z}\end{array}\right]$

The macro cutting model parameters of single crystal copper are shown in Table 3.

Table 3 Cutting model parameters

\begin{tabular}{llll}
\hline variable & value $(\mathrm{mm} / \mathrm{t} / \mathrm{s})$ & variable & value $(\mathrm{mm} / \mathrm{t} / \mathrm{s})$ \\
\hline workpiece material & single crystal copper & tool rake angle & 5 \\
tool material & hard alloy & tool clearance angle & 0 \\
workpiece Young modulus & $1.38 \mathrm{E}+11$ & tool arc radius & 0.2 \\
workpiece Poisson Ratio & 0.35 & tool thickness & 1 \\
tool Young modulus & $1.24 \mathrm{E}+10$ & depth of cut & 0.2 \\
tool Poisson Ratio & 0.3 & cutting distance & 2 \\
workpiece size & $10 \times 3 \times 1$ & cutting time & $1.0 \mathrm{E}-04$ \\
\hline
\end{tabular}

The finite element model of single crystal copper is shown in Fig.2. 


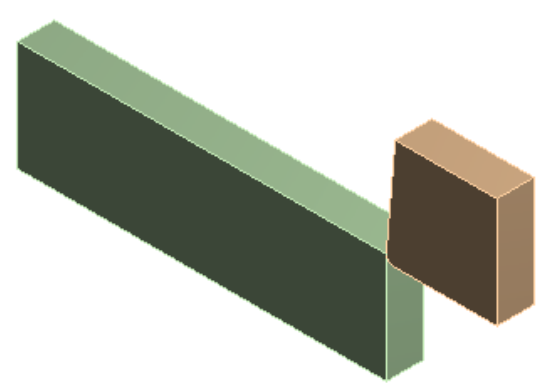

(a) cutting 3D model

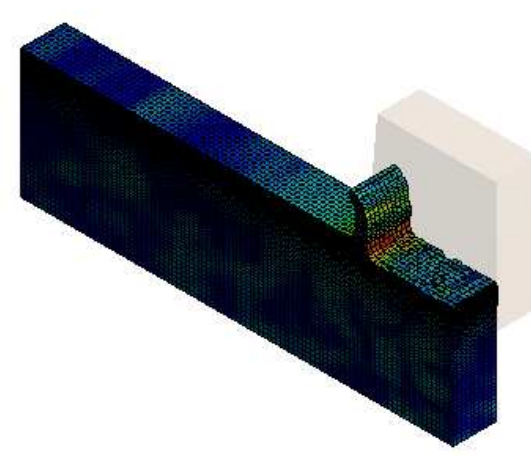

(c) chip model

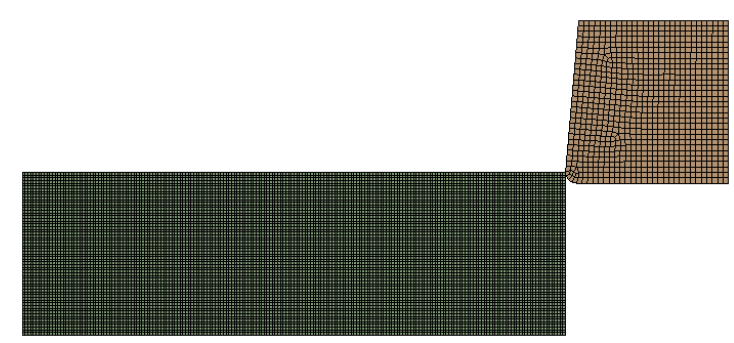

(b) cutting finite element model

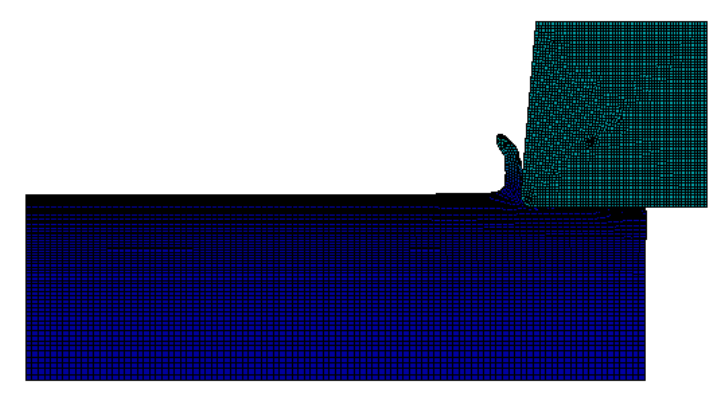

(d) main view of chip model

Fig.2 Metal cutting finite element model

In the process of establishing the metal cutting finite element model, in order to ensure the rationality and efficiency of the cutting process simulation, it is necessary to control the size of the workpiece element to make the size of the workpiece element in the cutting area as small as possible, and the size of the workpiece element away from the cutting area can be larger. At the same time, due to the high rigidity of the tool during the cutting process and almost no deformation, the size of the tool element can be a little larger than the size of the workpiece element, as is shown in Fig.2(b). The simulated cutting process is shown in Fig.2(c) and 2(d). It can be found that the cutting process of the workpiece and the generation of chip are realized through simulation, and the deformation of the chip conforms to the general orthogonal cutting simulation results.

\section{Analysis of cutting stress and cutting displacement of single crystal copper}

The distribution of stress and deformation in the process of hard alloy cutting single crystal copper are shown in Fig.3 (a) to Fig.3 (d). The minimum, maximum and average deformation values and stress values of the workpiece during the cutting process are shown in Fig.4 and Fig.5, The partial enlarged view of the cutting process is shown in Fig.6(a) to Fig.6(b). Among them, the green line in Fig.4 and Fig.5 represents the maximum value of deformation and stress, the blue line represents the average value of deformation and stress, and the red line represents the minimum value of deformation and stress. 

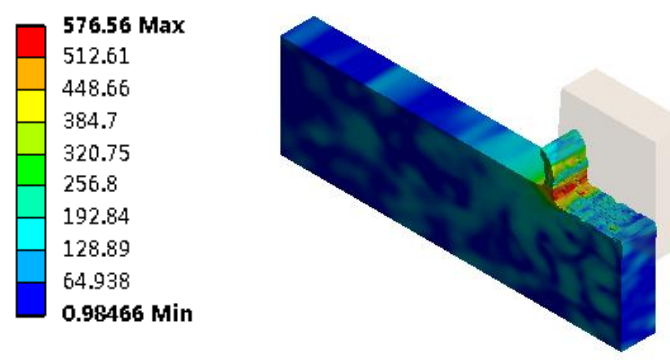

(a) diagram of cutting model stress

\begin{tabular}{|l|l|}
$\mathbf{7 . 5 7 4 9}$ Max \\
6.7332 \\
5.8916 \\
5.0499 \\
4.2083 \\
3.3666 \\
2.525 \\
1.6833 \\
0.84165 \\
0 Min
\end{tabular}

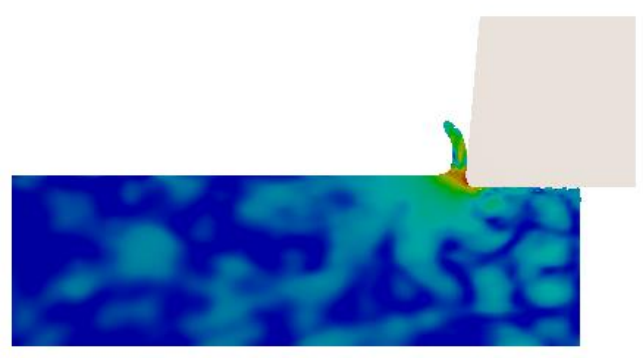

(b) front view of cutting model stress

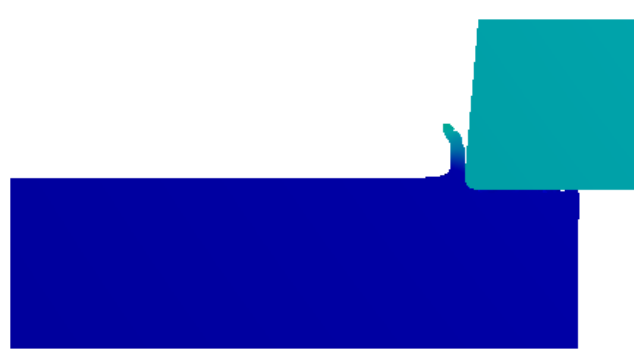

(d) front view of cutting model deformation

(c) deformation diagram of cutting model

Fig.3 Metal cutting stress and deformation diagram

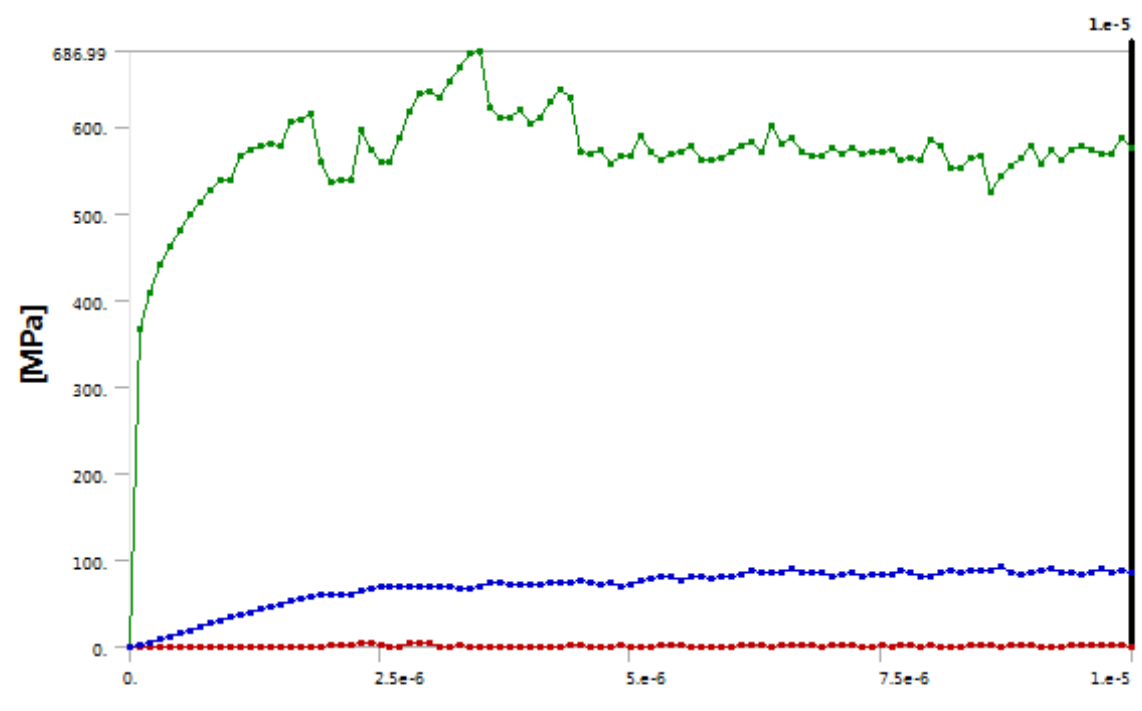

[s]

Fig.4 The minimum, maximum and average stress values of the workpiece during the cutting process 


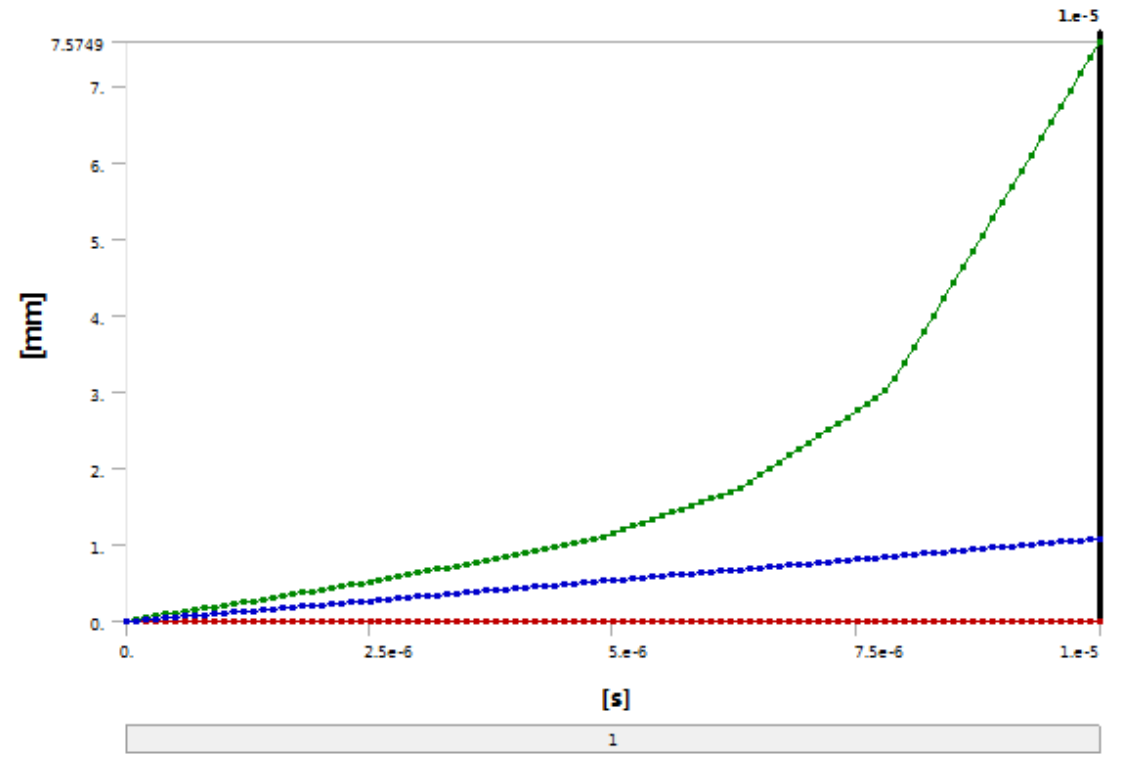

Fig.5 The minimum, maximum and average deformation values of the workpiece during the cutting process

It can be found from Fig. 4 that the maximum stress during the cutting process reaches $686.99 \mathrm{Mpa}$, which is much higher than the initial yield stress of copper of $89.63 \mathrm{Mpa}$. At the same time, it can be seen from Fig.3(a) and Fig.3(b) that the maximum stress occurs near the contact area between the tool and the workpiece. Finally, it can be found from Fig.4 that the average cutting stress during the cutting process is below $100 \mathrm{Mpa}$ and remains at a relatively stable and low value.

Then it can be found from Fig.5 that the maximum deformation of the metal during the cutting process reaches $7.5749 \mathrm{~mm}$, and it occurs at the end of the cutting process, and is the maximum deformation displacement of the chip at the same time. And from Fig.5, it can be found that the average deformation of the metal is increasing during the cutting process, and finally reaches nearly $1 \mathrm{~mm}$. In general, the average displacement remains at a low value.

Finally, from Figures 6(a) and 6(b), it can be found that in the cutting process, the chips produce a certain degree of bending, and as the cutting stroke increases, the chips will produce further bending deformation. The reason is that the metal copper has strong plasticity, so it is not easy to break when subjected to a certain external force, but produces bending deformation.

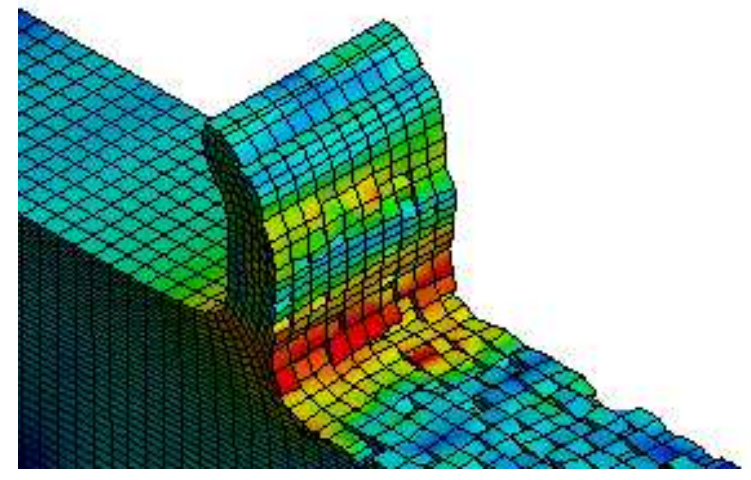

(a)partial view 1 of cutting model

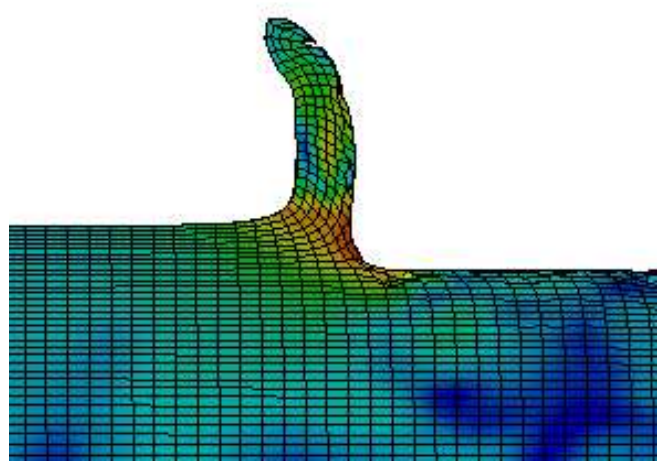

(a)partial view 2 of cutting model

Fig.6 Partial view of metal cutting 
It can be found from Fig.6(a) that the Johnson Cook failure criterion is adopted to achieve the separation of chip and workpieces, so the simulation model is reasonable and effective. From Fig. 6(b), it can be found that during the machining process, the stress on the upper surface of the workpiece is larger, while the stress on the lower surface is smaller. The reason is that there is a strong mutual extrusion between the tool and the upper surface of the workpiece during the cutting process, so the upper surface has a certain degree of plastic deformation during the cutting process, so there is still a certain residual stress on the upper surface after the cutting process is completed. The deformation of the lower surface is mainly small elastic deformation, and there is almost no residual stress after the cutting process is completed. Therefore, the stress on the upper surface is larger, and the stress on the lower surface is smaller.

\section{Analysis of single crystal copper cutting force}

Through simulation, the law of cutting force change during the cutting of single crystal copper can be obtained, as are shown in Figures 7(a) to 7(d).

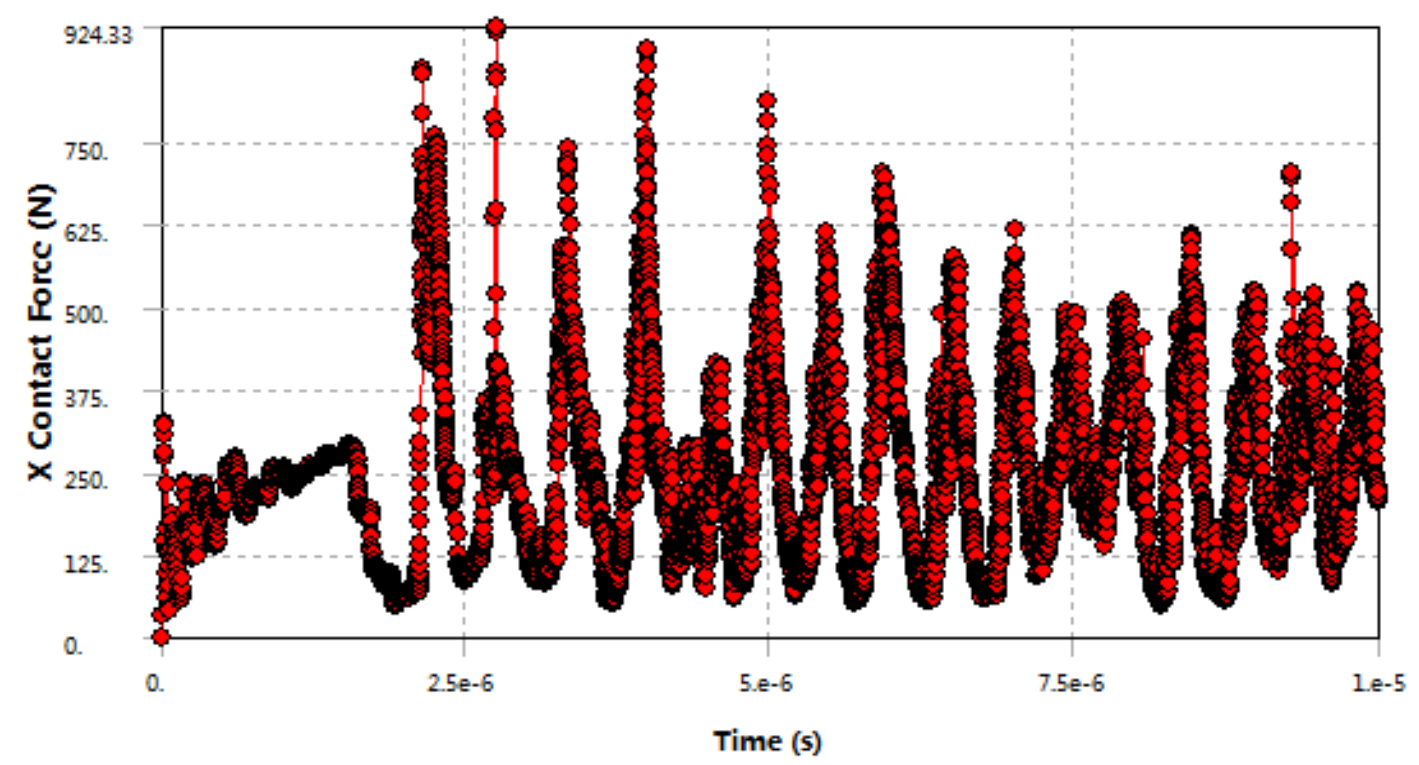

(a) cutting force in the $\mathrm{x}$ direction during single crystal copper cutting

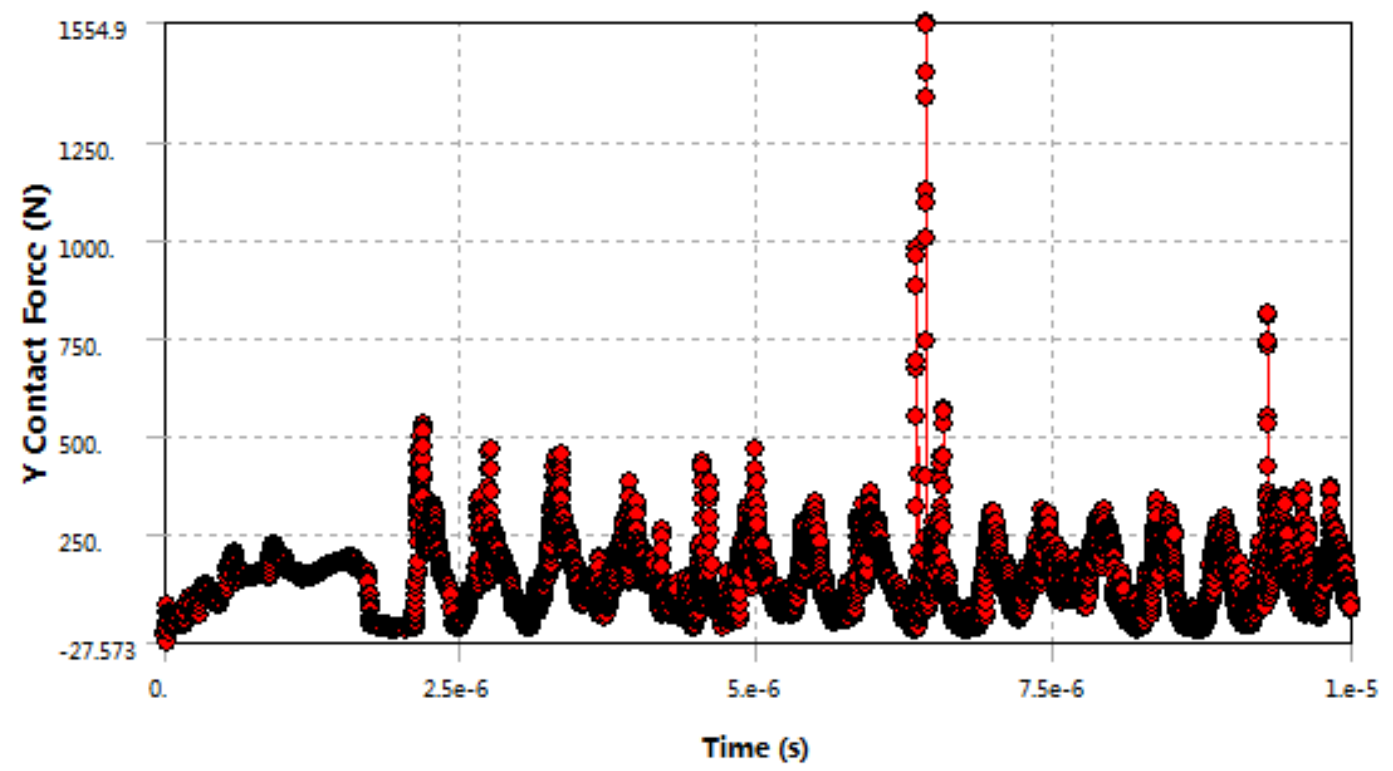


(b) cutting force in y direction during single crystal copper cutting

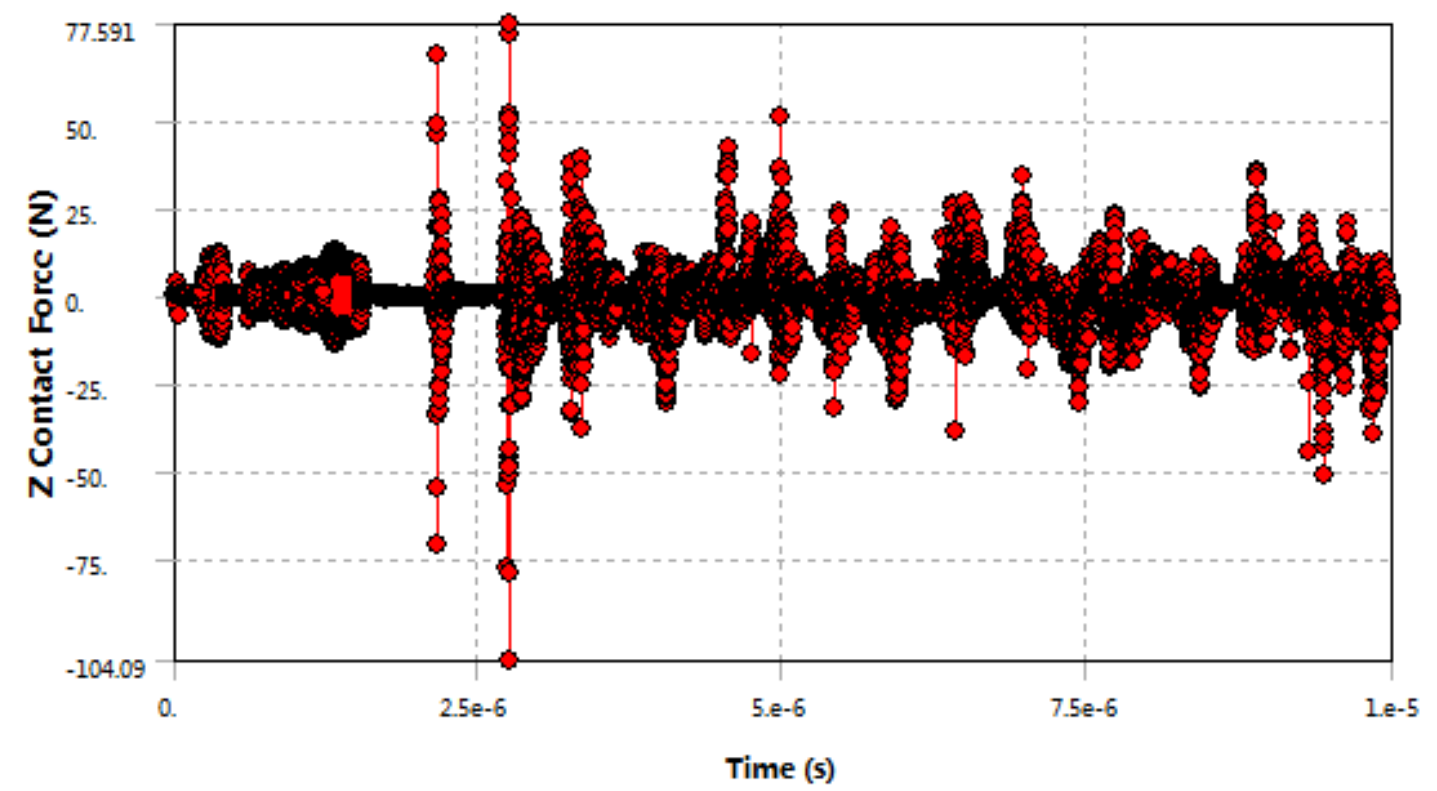

(c) cutting force in $\mathrm{z}$ direction during single crystal copper cutting

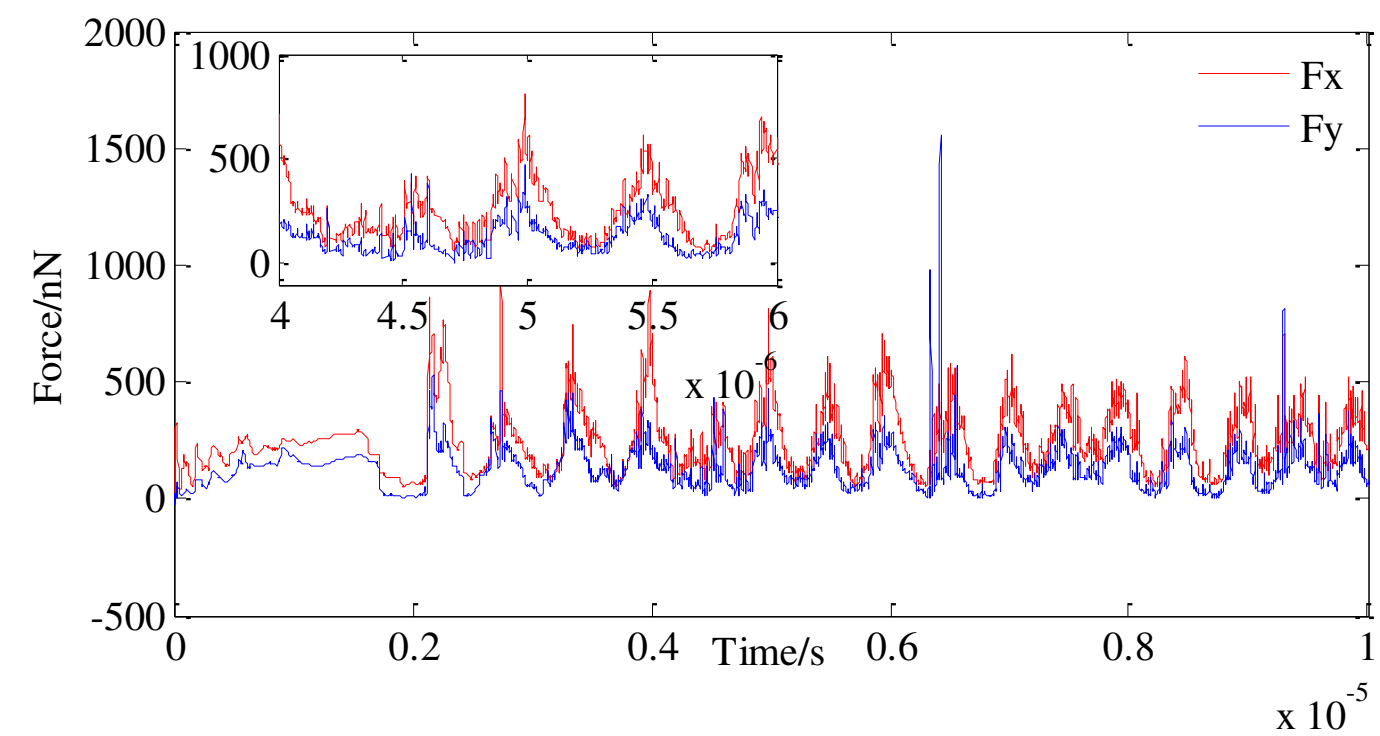

(d) cutting force in xyz direction and local time cutting force during single crystal copper cutting

Fig.7 Cutting force during single crystal copper cutting

The cutting force in three directions during the cutting process are shown in Fig.7(a) to 7(d). It can be found that the cutting force in the $\mathrm{x}$ direction is the largest, followed by the cutting force in the $\mathrm{y}$ direction, and the cutting force in the $\mathrm{z}$ direction is the smallest. The maximum cutting force in the $\mathrm{x}$ direction reached $924.33 \mathrm{~N}$, and the maximum cutting force in the $y$ direction reached $1554.9 \mathrm{~N}$. At the same time, the cutting force fluctuates up and down within a certain range, and the changing trend of the cutting force in the y direction is the same as that in the $\mathrm{x}$ direction. When the cutting force in the $\mathrm{x}$ direction is at the peaks and troughs, the cutting force in the $\mathrm{y}$ direction is also at the peaks and troughs. Finally, the average cutting forces in the $\mathrm{x}$ and $\mathrm{y}$ directions can be calculated, which are $249.9946 \mathrm{~N}$ and $129.6409 \mathrm{~N}$, respectively, as are shown in Fig.8. 


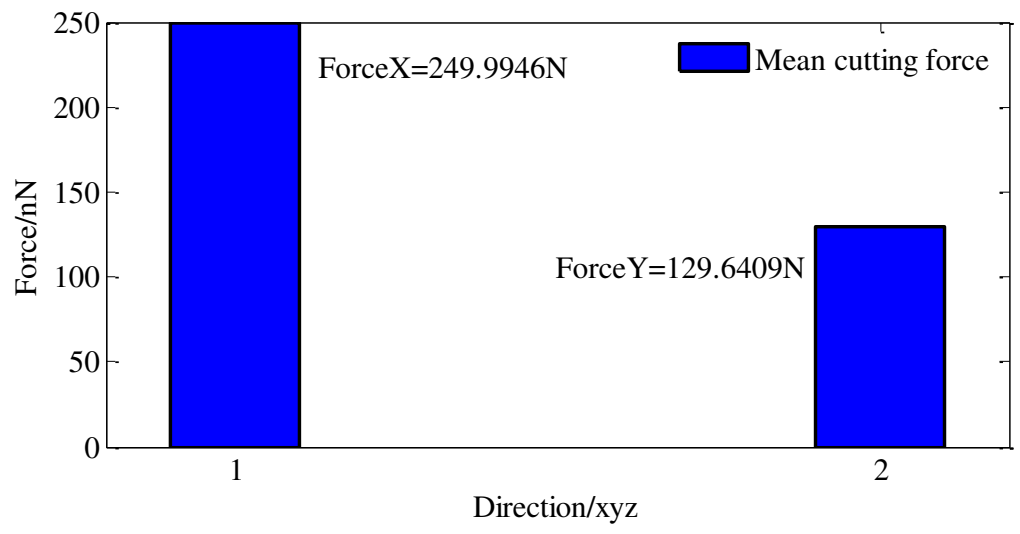

Fig. 8 The average cutting force in the metal cutting process in the finite element model

\section{Establishment of single crystal copper nano cutting model}

The single crystal copper nano cutting model is established by molecular dynamics simulation method. Molecular dynamics simulation method is a very effective method for simulating nanoscale physical phenomena, so it is widely used. The molecular dynamics simulation method is based on the basic theory of Newtonian mechanics. The interaction force between atoms follows Newton second law, namely:

$\sum_{j=1}^{n-1} F_{i j}=m a_{i}$

Among them: $n$ indicates that there are $n$ atoms in the system, $i$ indicates the $i$ atom, $j$ indicates the $j$ atom, $F_{i j}$ indicates the force of the atom $j$ on the atom $i$, and $m$ indicates the mass of the $i$ atom.

In molecular dynamics simulation, the Verlet algorithm is used to calculate the position and velocity of atoms. It obtains the position of time $t+\Delta t$ by the position of time $t-\Delta t$ and the acceleration of time $t$, and its formula is:

$\stackrel{\mathrm{r}}{r}(t+\Delta t)=2 \stackrel{\mathrm{r}}{r}(t)-\stackrel{\mathrm{r}}{r}(t-\Delta t)+\Delta t^{2} \underset{a}{\mathrm{r}}(t)$

Then the displacement distribution of the atoms is obtained, and the simulation of the dynamic characteristics of the atomic system is realized.

In order to study the similarities and differences of the cutting mechanism and cutting force in the macro and nano cutting process, a molecular dynamics model for simulating the cutting process of single crystal copper was established. In the macro finite element model, the tool material is hard alloy. However, in the process of simulating single crystal copper cutting process with molecular dynamics method, the tool rigidity is relatively large and basically no deformation occurs. Therefore, in order to facilitate the simulation, diamond is selected as the tool material. At the same time, in order to effectively compare the difference of macro and nano cutting performance, the macro model of alloy cutting single crystal copper is scaled to a certain degree. Specifically, the workpiece size of the macro cutting model is $10 \mathrm{~mm} \times 3 \mathrm{~mm} \times 1 \mathrm{~mm}$, the tool thickness is $1 \mathrm{~mm}$, the arc radius is $0.2 \mathrm{~mm}$, the cutting depth is $0.2 \mathrm{~mm}$, and the cutting distance is $2 \mathrm{~mm}$. The workpiece size of the molecular dynamics cutting model is $20 \mathrm{~nm} \times 6 \mathrm{~nm} \times 2 \mathrm{~nm}$, the tool thickness is $2 \mathrm{~nm}$, the arc radius is $0.4 \mathrm{~nm}$, the 
cutting depth is $0.4 \mathrm{~nm}$, and the cutting distance is $4 \mathrm{~nm}$. At the same time, ensuring that the rake and back angles of the two model tools are consistent. Finally, set the initial temperature of the molecular dynamics model to $300 \mathrm{~K}$. The parameters of the established single crystal copper molecular dynamics model are shown in Table 4.

Table 4 Cutting model parameters

\begin{tabular}{|c|c|c|c|}
\hline variable & $\begin{array}{l}\text { value } \\
(\mathrm{A} / \mathrm{g} / \mathrm{mol} / \mathrm{ps} / \mathrm{K})\end{array}$ & variable & $\begin{array}{l}\text { value } \\
(\mathrm{A} / \mathrm{g} / \mathrm{mol} / \mathrm{ps} / \mathrm{K})\end{array}$ \\
\hline workpiece material & Single crystal copper & depth of cut & 4 \\
\hline tool material & Diamond C & cutting distance & 40 \\
\hline workpiece size & $200 \times 60 \times 20$ & cutting time & 4 \\
\hline tool rake angle & $5^{\circ}$ & potential function between $\mathrm{Cu}$ & EAM \\
\hline tool clearance angle & $0^{\circ}$ & potential function between $\mathrm{C}$ & Tersoff \\
\hline tool arc radius & 4 & potential function between $\mathrm{Cu}$ and $\mathrm{C}$ & Morse \\
\hline tool thickness & 20 & initial temperature & 300 \\
\hline
\end{tabular}

The established molecular dynamics model of diamond cutting single crystal copper is shown in Fig.9. Fig.9(a) is the front view of the molecular dynamics model, and Fig.9(b) is the threedimensional view of the molecular dynamics model. In the model, set the fixed layer, thermostatic layer and newtonian layer. The fixed layer plays the role of fixing the boundary of the simulation system, the thermostatic layer plays the role of maintaining the temperature of the simulation system, and the newtonian layer plays the role of contact between the atomic layers.

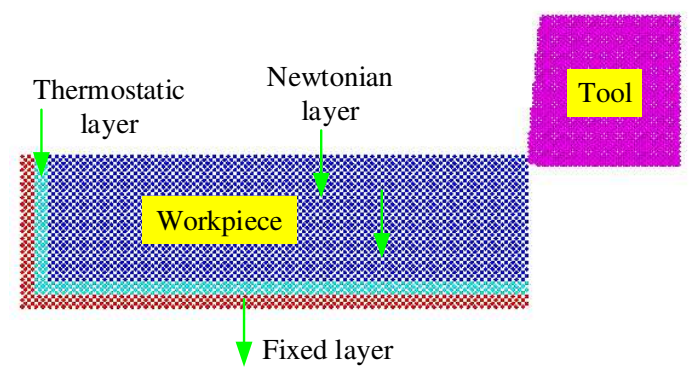

(a) front view of nano cutting model

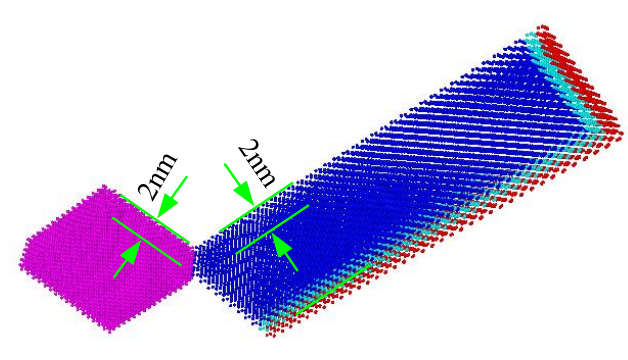

(b) $3 \mathrm{D}$ view of nano cutting model

Fig.9 Molecular dynamics model of diamond cutting single crystal copper

\section{Analysis of nano cutting stress and cutting displacement of single crystal copper}

In order to analyze the similarities and differences of cutting stress and cutting displacement in the cutting process of macro and nano single crystal copper, the stress field and displacement field of the molecular dynamics model of single crystal copper were analyzed. Stress field analysis is to analyze the stress of the entire workpiece in the cutting process, and displacement field analysis is to analyze the deformation of the workpiece in the cutting process.

In the molecular dynamics model of single crystal copper, first calculate the 6 direction stress $\sigma_{x}, \sigma_{y}, \sigma_{z}, \tau_{x y}, \tau_{x z}, \tau_{y z}$ of a single atom, and then calculate the vonmises stress based on the above 6 direction stress. The calculation formula is: 


$$
\sigma_{\text {vonmises }}=\sqrt{\frac{\left(\sigma_{x}-\sigma_{y}\right)^{2}+\left(\sigma_{x}-\sigma_{y}\right)^{2}+\left(\sigma_{x}-\sigma_{y}\right)^{2}+6\left(\tau_{x y}^{2}+\tau_{x z}^{2}+\tau_{x z}^{2}\right)}{2}}
$$

The specific stress field analysis results are shown in Fig.10. It can be found from Fig.10 that during the nano cutting process of single crystal copper, the maximum vonmises equivalent stress reaches about $60 \mathrm{Gpa}$, and the stress is the largest in the contact area between the workpiece and the tool, followed by the stress near the contact area, and the smaller the stress far from the contact area.
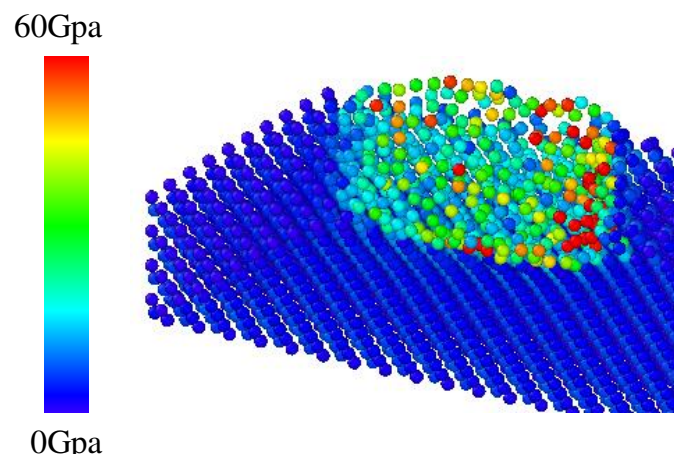

(a) diagram 1 of single crystal copper vonmises cutting stress

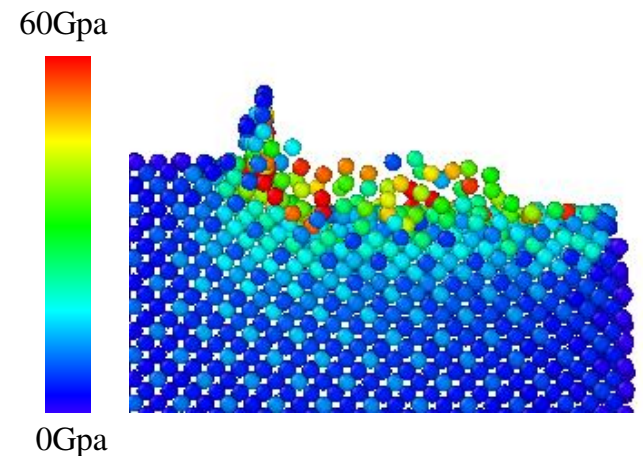

(b) diagram 2 of single crystal copper vonmises cutting stress

Fig.10 vonmises stress during single crystal copper cutting

In order to analyze the displacement field of single crystal copper, the largest displacement atom in the Y direction of single crystal copper is selected for analysis. By selecting the atom numbered 5364 for analysis, the maximum displacement of the atom during the cutting of single crystal copper can be obtained, as is shown in Fig.11. It can be found that during the cutting process, the maximum displacement of the single crystal copper atom in y direction is $0.7846 \mathrm{~nm}$, and the chip length is approximately $1.1846 \mathrm{~nm}$ (considering the cutting depth). In the cutting process, the cutting distance is $4 \mathrm{~nm}$, and it can be calculated that the chip length is about $30 \%$ of the cutting distance. It can be found that in the nano cutting process, the chip length is small, and the reason is still closely related to the extremely small cutting depth and the change of the cutting mechanism from macro to nano.

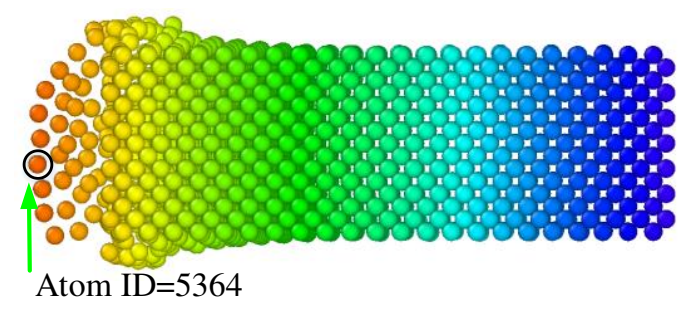

(a) atom number 5364 of single crystal copper

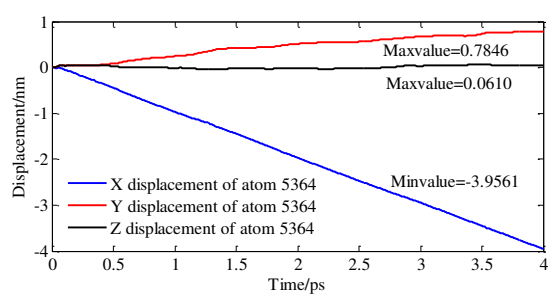

(b) displacement of a atom number 5364 of single crystal copper

Fig.11 The xyz direction displacement changes of the atom with maximum displacement of single crystal copper

\section{Nano cutting force analysis of single crystal copper}

Through molecular dynamics model simulation, the diamond cutting single crystal copper cutting process can be simulated, as are shown in Fig.12 (a) to Fig.12(d). From Fig.12(a) to 12(c), it can be found that during the cutting process, a band of continuous chip is formed, and the chip are tightly on the rake face of the tool. By comparing Fig.12(c) and Fig.6(b), it can be found that in the macro 
cutting model, the chip gradually become curved, while in the molecular dynamics model, the chips are linear and attached to the tool surface. This is one of the differences between the macro cutting process and the nano cutting process. The reason is the difference in the force between substances of different scales. In the macro scale cutting process, the elastic and plastic stress play the leading role, while in the nano scale cutting process, the van der Waals force and electrostatic force between atoms play the leading role,as is shown if Figure13. This leads to the difference of formation mechanism of chip in the nano cutting process. Attracted by the atoms of the workpiece on the rake face, the chips are closer to the rake face of the tool rather than bend.
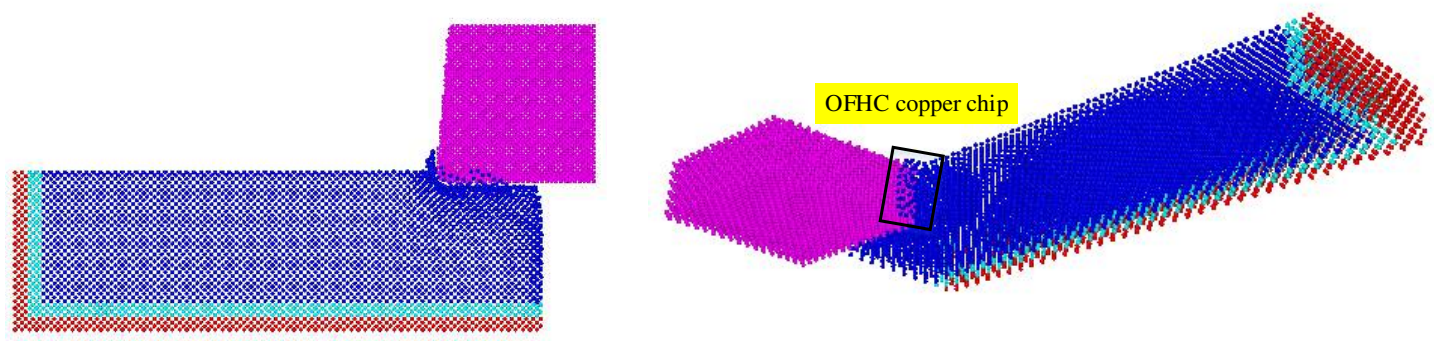

(a) front view of cutting model

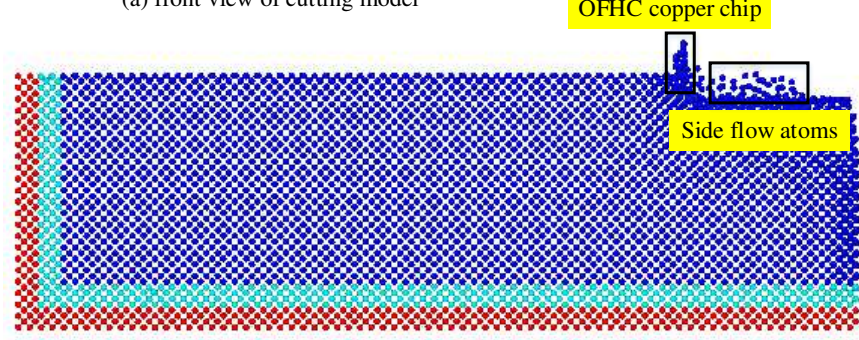

(c) cutting process model (b) 3D viewing of cutting model

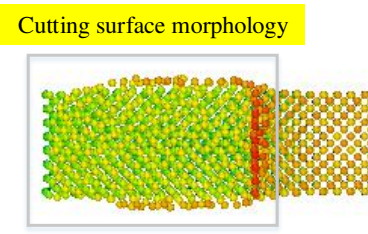

(d) cutting surface topography

Fig.12 Process model of diamond cutting single crystal copper

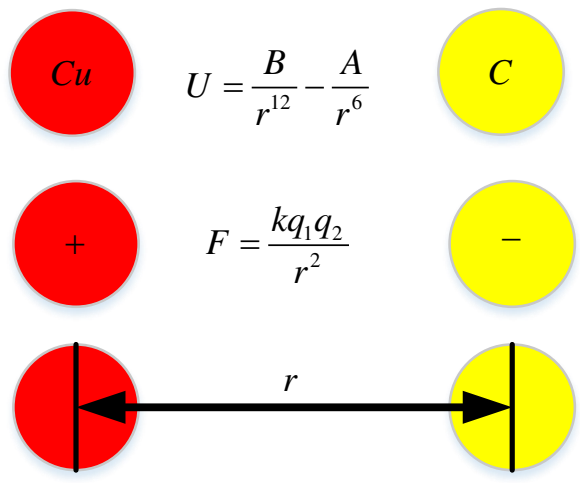

Van der Waals force

Electrostatic force

\section{Atom distance}

Fig.13 Interatomic van der Waals force and electrostatic force 


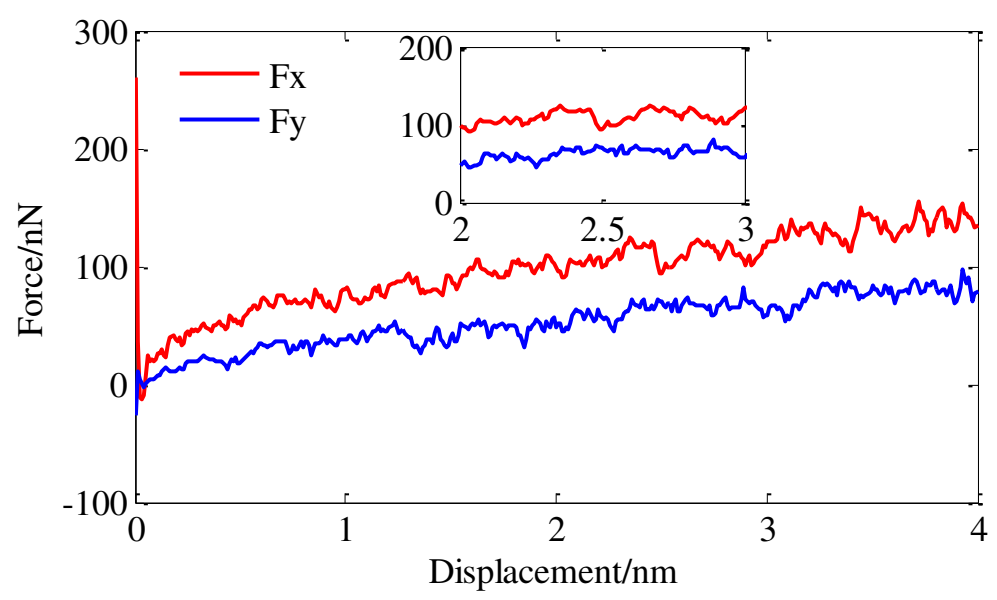

Fig.14 Cutting force of diamond cutting single crystal copper

Fig. 14 shows the change of cutting force during molecular dynamics simulation. It can be found that in the nano cutting model, the cutting force in the $\mathrm{x}$ direction is greater than the cutting force in the y direction, and the cutting force fluctuates up and down to a certain extent, which is consistent with the change law of the macro cutting model. Different from the macro cutting force model, in the macro cutting model, the cutting force fluctuates within a certain range, while in the nano cutting model, the cutting force shows an increasing trend. The reason is that in the nano cutting process, the cutting depth is extremely small, only reaches $0.4 \mathrm{~nm}$, so the formation of chips is more difficult, which causing a large number of workpiece atoms to accumulate on the rake face of the workpiece, thus making the cutting force slowly increase. As is shown in Fig.15. At the same time, in the nano cutting model, the maximum cutting force in the $\mathrm{x}$ direction is $154.5231 \mathrm{nN}$ (ignoring the initial abnormal cutting force in the $\mathrm{x}$ direction), and the maximum cutting force in the $\mathrm{y}$ direction is $97.7992 \mathrm{nN}$. Finally, the average values of the cutting forces in the $\mathrm{x}$ direction and $\mathrm{y}$ direction are calculated, which are $96.7 \mathrm{nN}$ and $51.9 \mathrm{nN}$, respectively. As is shown in Fig.16.

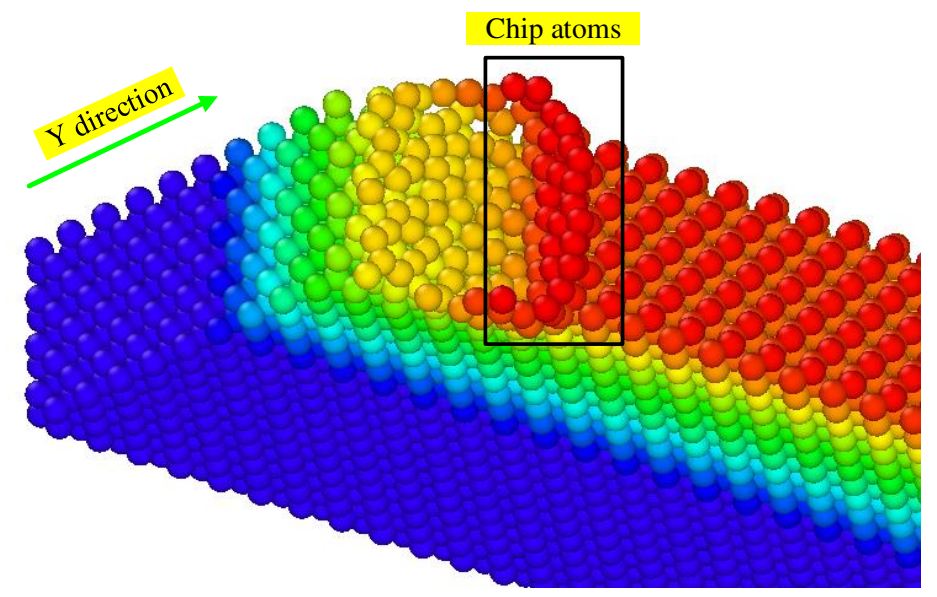

Fig.15 Chip atom formation process during nano cutting 


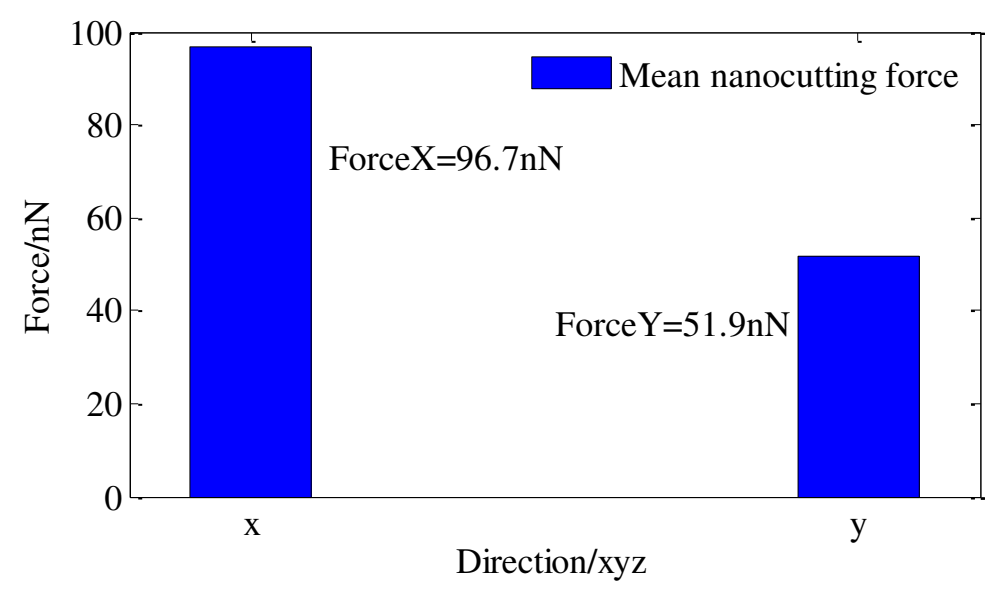

Fig.16 The average cutting force in the metal cutting process in the molecular dynamics model

9 Comparison analysis between macro and nano cutting characteristics and mechanism of single crystal copper

In order to compare the difference of cutting performance in the macro and nano cutting process, the cutting forces in $\mathrm{x}$ and $\mathrm{y}$ direction at 10 points between $0 \mathrm{~mm}$ and $2 \mathrm{~mm}$ in the macro cutting process are selected as two sets of data, and the 10 points between $0 \mathrm{~nm}$ and $4 \mathrm{~nm}$ in the nano cutting process are also selected. The cutting force in the $\mathrm{x}$ direction and $\mathrm{y}$ direction in the two types of data are respectively compared, and then analyzed. The comparative analysis results are shown in Fig.17 and Fig.18.

\subsection{Comparative analysis of cutting force}

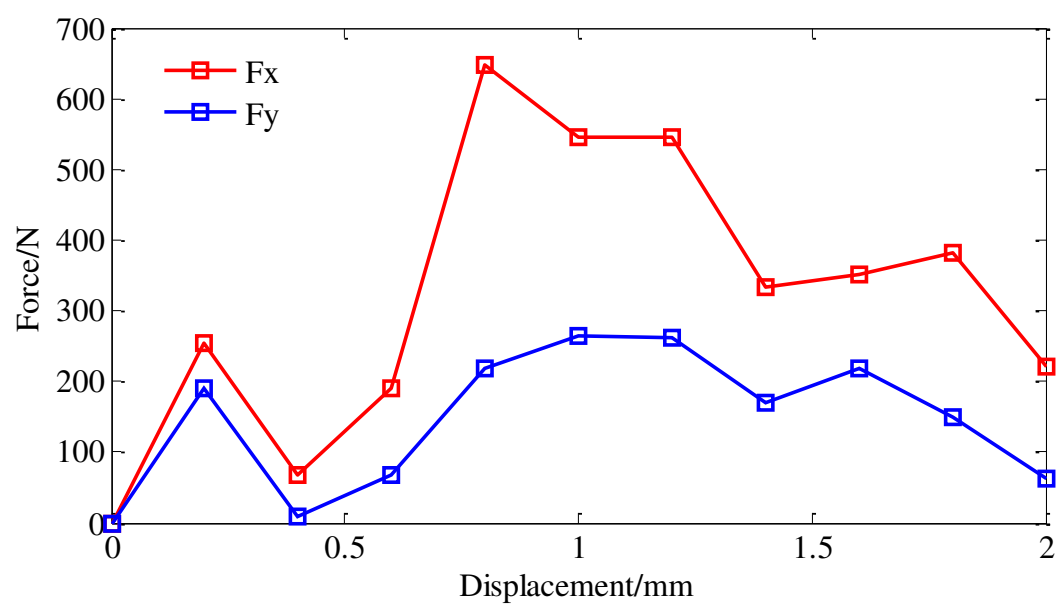

Fig.17 The relationship between cutting force and cutting distance in the macro cutting process 


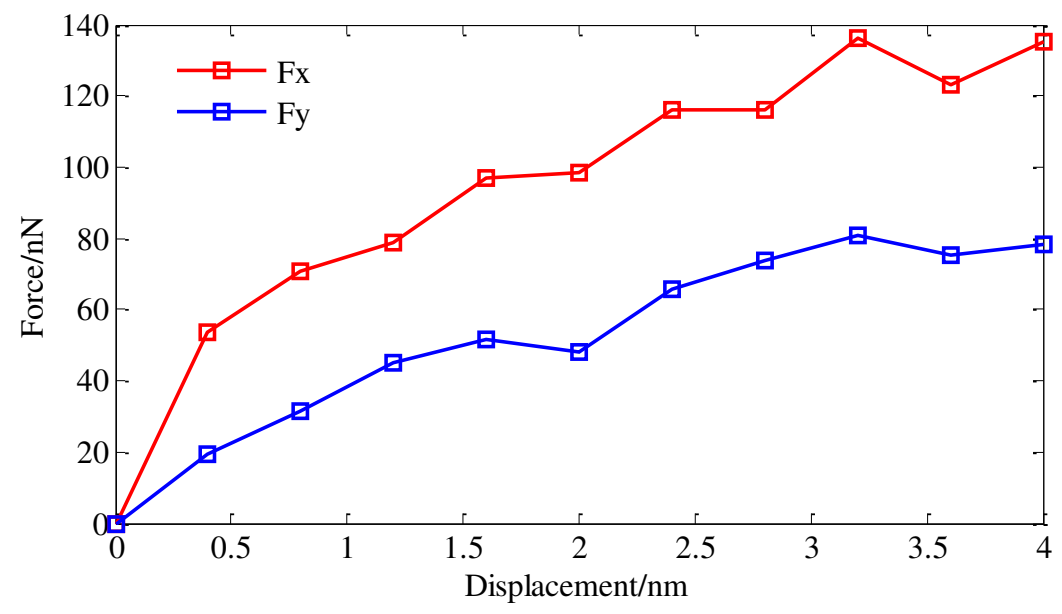

Fig.18 The relationship between cutting force and cutting distance in the nano cutting process

It can be found from Fig. 17 that in the macro cutting process, the change trend of the cutting force in the $\mathrm{y}$ direction and the cutting force in the $\mathrm{x}$ direction is basically the same. When the cutting force in the $\mathrm{x}$ direction increases, the cutting force in the $\mathrm{y}$ direction increases, and vice versa. It can be found from Fig. 18 that in the nano cutting process, the cutting force in the y direction and the cutting force in the $\mathrm{x}$ direction have basically the same changing trends. However, unlike macro cutting, the cutting force in the nano cutting process shows a slow increase trend, while the cutting force in the macro cutting process shows a fluctuating trend. The reason for the difference in the law of cutting force changes between the two is that the cutting depth in nano cutting is extremely small. It is difficult to form chips during the nano cutting process. At the same time, the macro and nano cutting force can be further compared and analyzed. Specifically, by calculating the relationship between the ratio of cutting force in the $\mathrm{x}$ direction and the $\mathrm{y}$ direction of the macro and nano cutting process, and then studying the corresponding relationship of the macro and nano cutting force, it is possible to further understand the similarities and differences of the cutting characteristics in the macro and nano cutting process. As is shown in Fig.19. It can be found that the corresponding ratios of cutting force in $\mathrm{x}$ and $\mathrm{y}$ direction during the macro and nano cutting process are very close. It can be infered that the cutting force characteristics in the macro and nano cutting process have a high degree of similarity. Furtherly, it is possible to analyze the ratio of the average cutting force in the $\mathrm{x}$ direction and $\mathrm{y}$ direction between macro and nano cutting process, so as to realize the indepth analysis of the comparison of the cutting characteristics in the macro and nano cutting process. As is shown in Fig.20. It can be found from the Fig.that the corresponding ratios of the average values of the macro and nano cutting forces in the $\mathrm{x}$ and $\mathrm{y}$ directions are very close, which further verifies the similarity of the cutting forces in the macro cutting and nano cutting processes. 


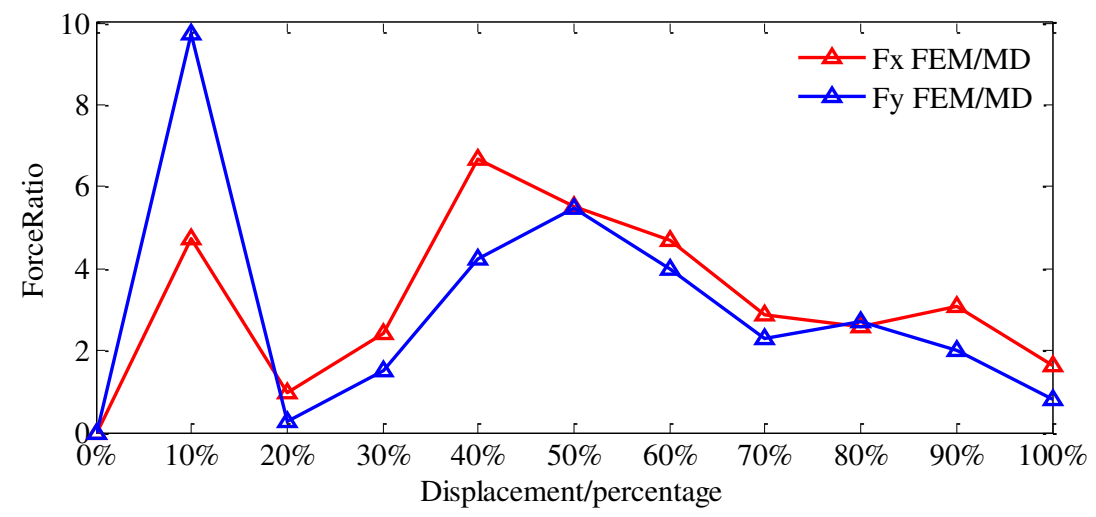

Fig.19 The ratio of cutting forces between macro and nano cutting process in $\mathrm{x}$ and $\mathrm{y}$ directions

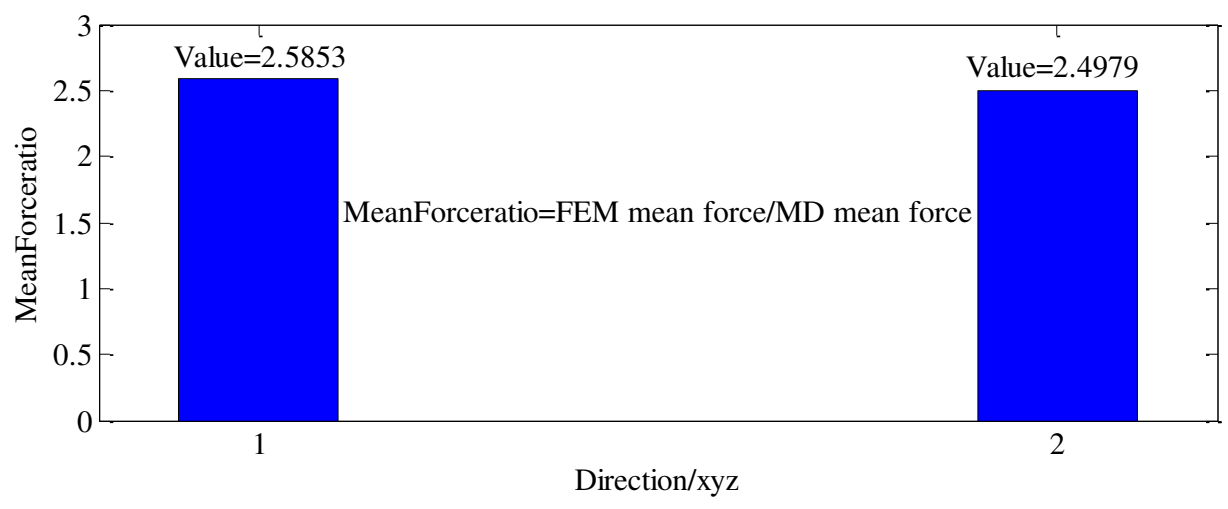

Fig.20 The ratio of the average cutting force between macro and nano cutting process

\subsection{Comparative analysis of cutting stress}

The macro and nano cutting stress analysis is shown in Fig.21. It can be found from Fig.21 that at the end of the cutting process, the macro cutting vonmises equivalent stress reaches a maximum value of $576.56 \mathrm{Mpa}$, while the nano cutting vonmises equivalent stress reaches a maximum of 60Gpa. It can be found that the cutting stress in the nano cutting process is about 100 times the macro cutting stress. In the nano cutting process, the atomic interaction force is stronger. At the same time, it can be found that in the cutting process, there is a certain residual stress on the cutting surface of the macro and nano process. This residual causes a certain plastic deformation of the cutting surface of the workpiece, which in turn causes the quality of the cutting surface to decrease and the roughness to increase. Therefore, it is necessary to try to control the residual stress, so as to ensure the accuracy of the machined surface.

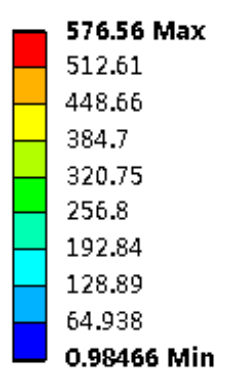

(a) vonmises stress of FEM simulation

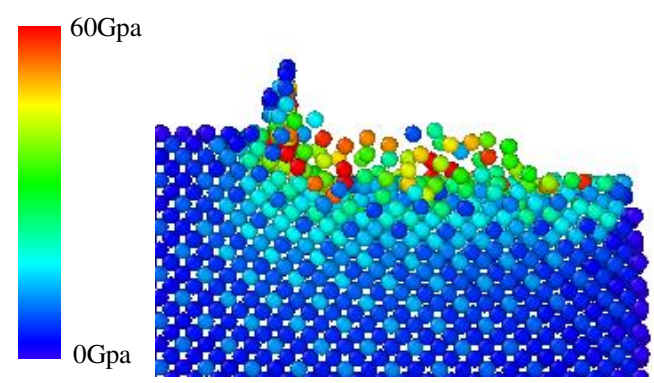

(b) vonmises stress of MD simulation

Fig.21 Comparison of macro and nano cutting stress 


\subsection{Comparative analysis of chip morphology}

The macro and nano chip morphology analysis is shown in Fig.22. It can be found from Fig.22 that the chip length in the macro cutting process is larger than the chip length in the nano cutting process, and the shape is more regular. The reason is the difference between the macro cutting and nano cutting mechanisms. In the macro cutting process, the generation of chips is due to the strong shearing force of the metal near the tool, which has strong directionality, so that the chip shape is regular. In the nano cutting process, the generation of chips is due to the contact between the workpiece atoms and the tool atoms, so the direction of the force has a certain randomness, which resulting in irregular chip shape. At the same time, due to the extremely small depth of cut, it is difficult to generate chips, which making the chip length is relatively small in the nano cutting process.

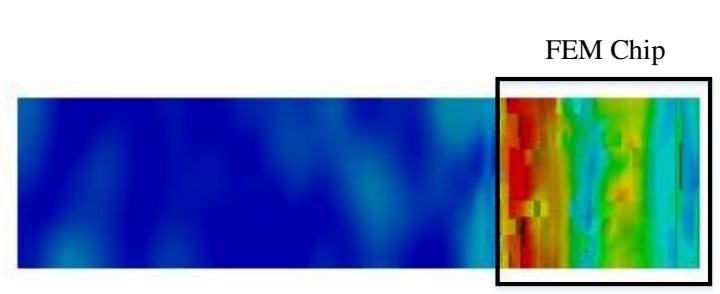

(a) chip of FEM simulation

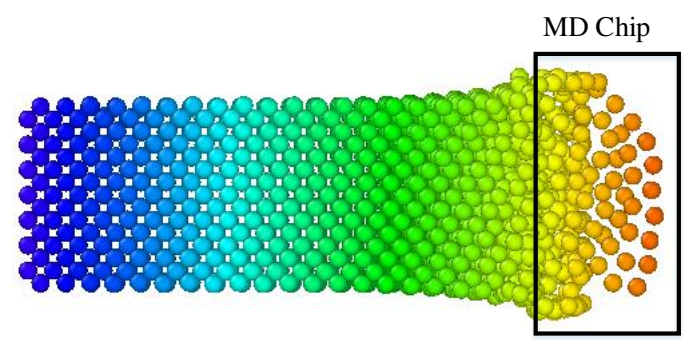

(b) chip of MD simulation

Fig.22 Comparison of macro and nano chip morphology

\section{Experiment verification}

In order to verify the rationality and validity of the finite element analysis results in the macro cutting process, experiment method is used for comparative analysis. Through the implementation of single crystal copper cutting experiments, the cutting force data during the cutting process is obtained, and the chip morphology after copper cutting is obtained at the same time. In order to compare with the simulation results, the material of the workpiece and the tool, the feed displacement and cutting depth of the tool, the rake and relief angle of the tool, the measurement object and the cutting method should be consistent with the simulation model during the cutting process. Specifically, during the experiment, OFHC(oxygen free high conductance)copper is used as the cutting material, and its copper content is more than $99.9999 \%$, which can be regarded as a single crystal copper material. The tool material adopts tungsten-cobalt-titanium hard alloy material, which is a widely used tool for machining ductile metal materials. The feed displacement of the tool is $0.2 \mathrm{~mm} / \mathrm{r}$, the depth of cut is $1 \mathrm{~mm}$, the rake angle of the tool is $5^{\circ}$, the relief angle is $0^{\circ}$, the measured variable is the tangential cutting force $\mathrm{Fc}$ ( $\mathrm{Fx}$ in the simulation model), the feed cutting force $\mathrm{Ff}$ ( $\mathrm{Fy}$ in the simulation model) and radial cutting force $\mathrm{Fp}$ (Fz in the simulation model). The cutting method is ordinary external turning. The entire cutting experiment was carried out in Chongqing Dijia Technology Co., Ltd. (former Dixi CNC Research Institute of Chongqing University). The specific experimental parameters are shown in Table 5. The established experimental platform is shown in Fig.23.

Table 5 Cutting experiment parameters

\begin{tabular}{llll}
\hline Variable & Value $(\mathrm{mm} / \mathrm{t} / \mathrm{s} / \mathrm{r})$ & Variable & Value $(\mathrm{mm} / \mathrm{t} / \mathrm{s} / \mathrm{r})$ \\
\hline
\end{tabular}




\begin{tabular}{llll}
\hline Workpiece material & OFHC copper & Tool rake angle & 5 \\
Tool material & Cemented Carbide & Tool clearance angle & 0 \\
Tool feed & 0.2 & Measuring object & Fc,Ff,Fp \\
Cutting depth of tool & 1 & Cutting method & Ordinary external turning \\
\hline
\end{tabular}

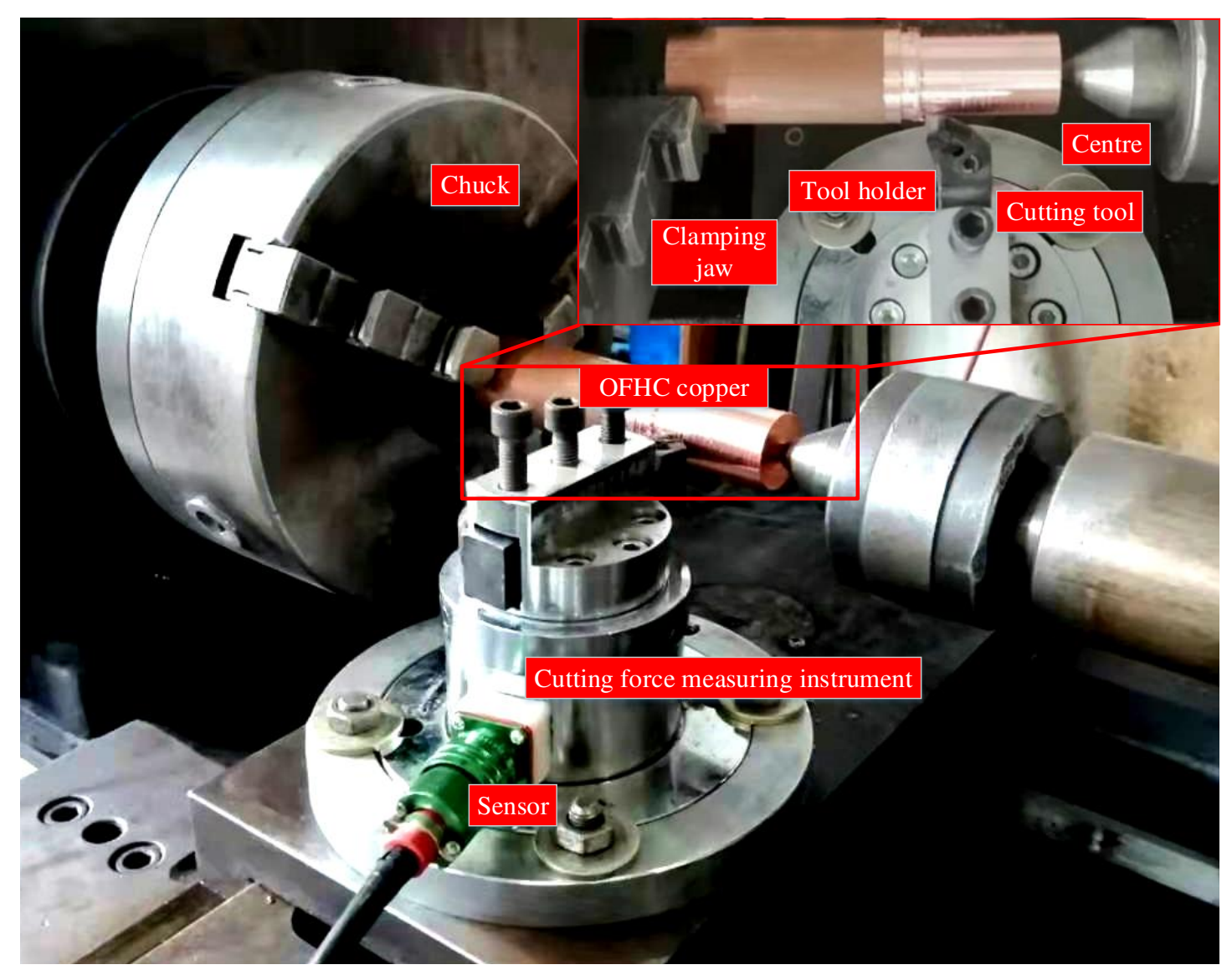

Fig.23 Macro cutting experiment of single crystal copper
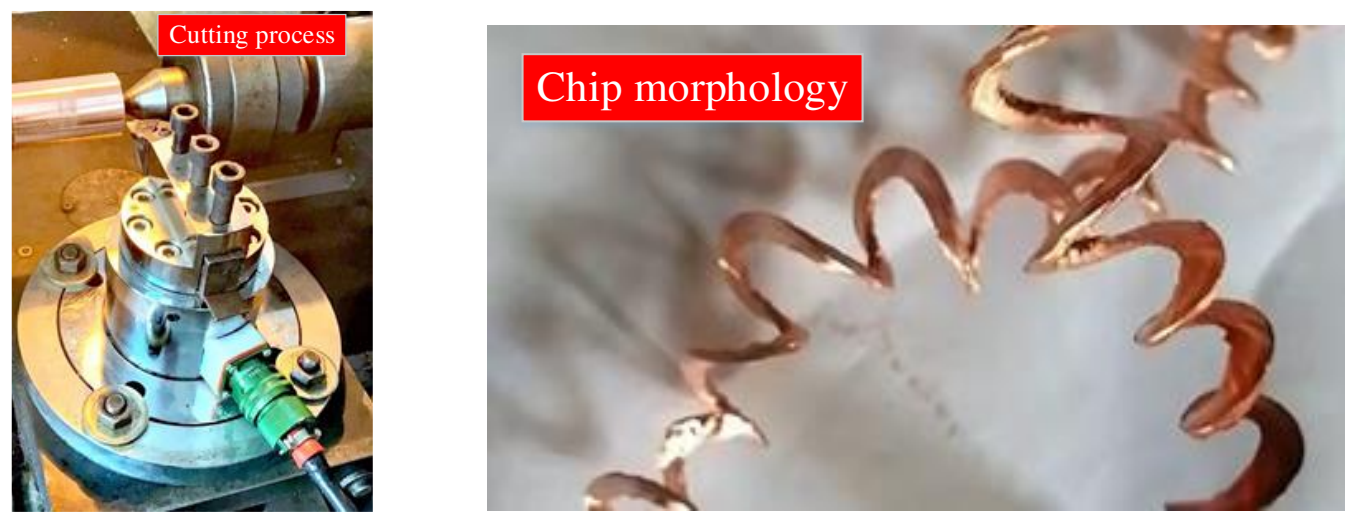

Fig.24 Single crystal copper cutting process

Fig.25 Chip morphology during single crystal copper cutting

The experimental process is shown in Fig.24, and the morphology of the metal copper chips after the cutting process can be obtained, as is shown in Fig.25. In Fig.23, the tool is installed on the cutting force measuring instrument to realize the measurement of the force on the tool during the cutting process, which is then converted to the measurement of the cutting force. After the cutting process is completed, the shape of the chip can be obtained. Through observation, it can be found 
that the chip is in a spiral band. The reason is that the tool moves spirally relative to the workpiece during the external turning process, and the thickness of the chip remains unchanged after the first circle of the turning process, so the cutting chip appears spiral band shape.

Through cutting experiments, the tangential and radial cutting forces between the workpiece and tool can be obtained, as is shown in Fig.26. At the same time, the finite element simulation cutting force results can be compared with the experimental cutting force results, as are shown in Fig.27 and Fig.28. Through the comparative analysis of Fig.7(d) and Fig.26, it can be found that the simulation cutting force change trend is very similar to the experimental cutting force change trend, and both fluctuate up and down within a certain range. By observing Fig.27 and Fig.28, it can be found that the experimental tangential cutting force is greater than the simulated tangential cutting force, and the experimental radial cutting force is also greater than the simulated radial cutting force. The reason may be the following two aspects: 1 . The arc radius of the cutting edge of the tool in the simulation model is inaccurate, resulting in a small cutting force in the simulation model. 2. The experimental tool is worn and the precision of the experimental machine is not high, resulting in large experimental cutting forces.

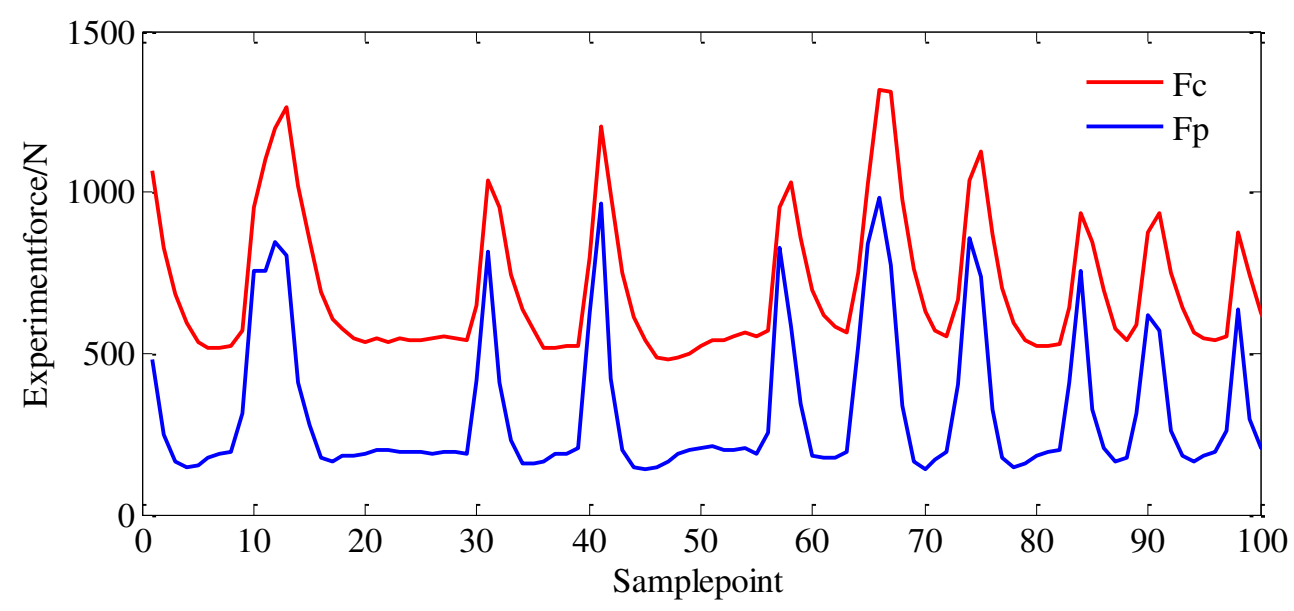

Fig.26 Cutting force during single crystal copper cutting

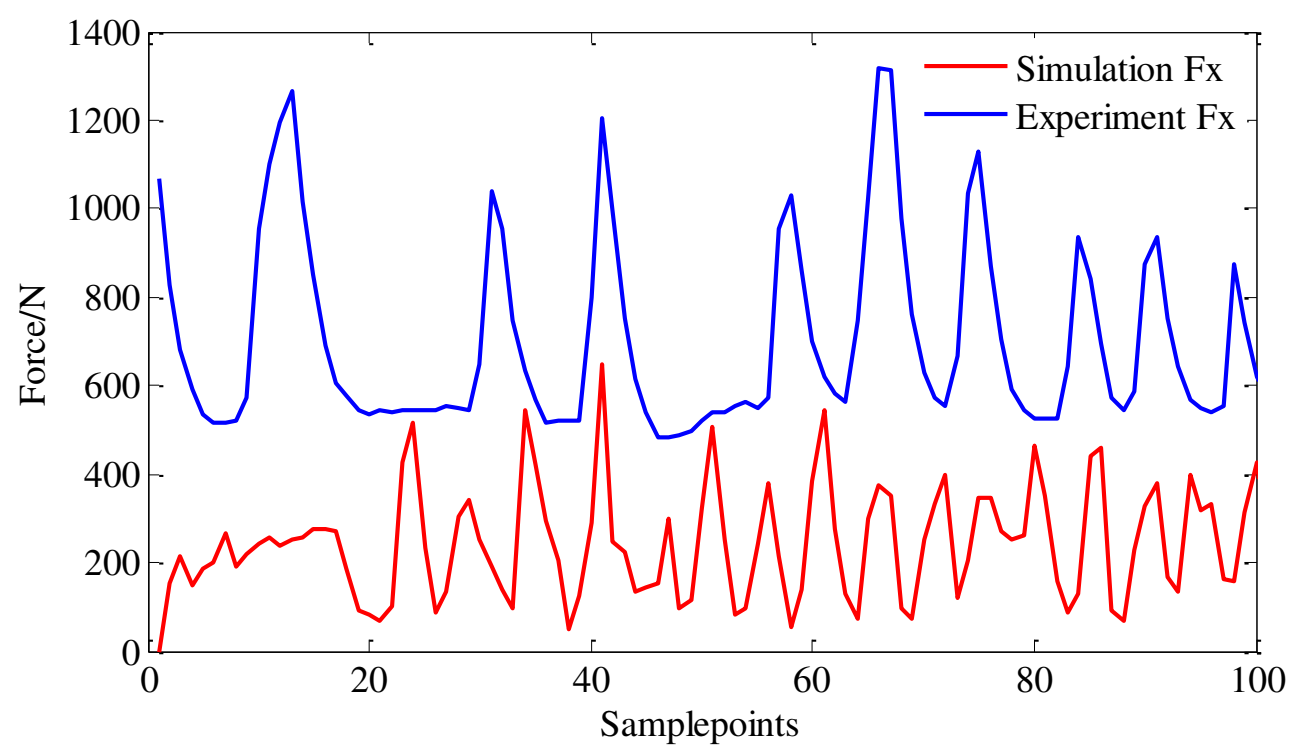

Fig.27 Simulation and experimental comparison of cutting force in the $\mathrm{x}$ direction of single crystal 


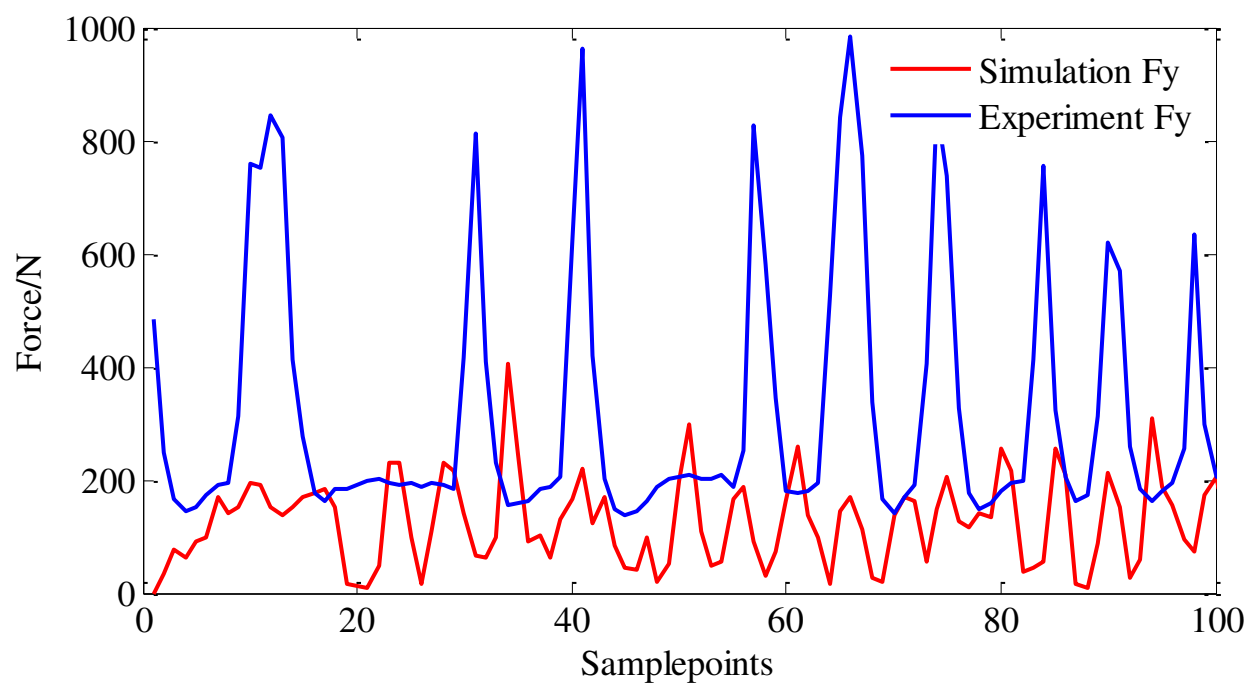

Fig.28 Simulation and experimental comparison of cutting force in the y direction of single crystal copper

\section{Conclusion}

The paper carried out finite element simulation and molecular dynamics simulation on the macro and nano cutting process of single crystal copper respectively, obtaining the cutting force, cutting stress, cutting displacement and chip morphology in the macro and nano cutting process, and compared the simulation results. The difference between macro and nano cutting characteristics is analyzed, and the reasons for the difference between the two are discussed. At the same time, the external turning experiment was carried out on the macro cutting process, and the cutting force during the external turning experiment was obtained. The experimental cutting force and the simulated cutting force were compared and analyzed to verify the rationality and validity of the simulation results. At the same time, the reasons for the difference between the two are analyzed. The paper has the following conclusions:

(1) In the process of macro and nano cutting, the change trend of the cutting force in the y direction and the cutting force in the $\mathrm{x}$ direction is basically the same. When the cutting force in the $\mathrm{x}$ direction increases, the cutting force in the y direction increases, and vice versa. However, unlike macro cutting, the cutting force in the nano cutting process shows a slow increase trend, while the cutting force in the macro cutting process shows a fluctuating trend. The reason for the difference in the trend of cutting force changes between the two is that the cutting depth in nano cutting is extremely small. It is difficult to form chips during the nano cutting process. At the same time, the corresponding ratio of the cutting force between the macro and nano cutting process in the $\mathrm{x}$ and $\mathrm{y}$ directions are very close and the corresponding ratio of the value of average cutting force between the macro and nano cutting forces in the $\mathrm{x}$ and $\mathrm{y}$ directions are also very close, indicating that the cutting force characteristics in the macro and nano cutting process have a high degree of similarity. (2) At the end of the cutting process, the macro cutting vonmises equivalent stress reaches a maximum of $576.56 \mathrm{Mpa}$, while the nano cutting vonmises equivalent stress reaches a maximum of $60 \mathrm{Gpa}$. It can be found that the cutting stress during nano cutting is about 100 times the macro cutting stress, indicating that the interaction force between atoms in the nano cutting process is 
stronger.

(3) The chip length in the macro cutting process is larger than the chip length in the nano cutting process, and the shape is more regular. The reason is the difference between the cutting mechanisms of macro and nano cutting.

(4) The experimental cutting force change trend is very similar to the simulation cutting force change trend, and both fluctuate up and down within a certain range. The difference is that the experimental tangential cutting force is greater than the simulated tangential cutting force, and the experimental radial cutting force is also greater than the simulated radial cutting force. The reason may be the following two aspects: 1 . The arc radius of the cutting edge of the tool in the simulation model is inaccurate, resulting in a small cutting force in the simulation model. 2. The experimental tool is worn and the precision of the experimental machine is not high, resulting in large experimental cutting forces.

\section{Declarations}

Funding The work is supported by professor Dongju Chen of Beijing university of technology.

Conflicts of interest/Competing interests The authors declare no competing interest.

Availability of data and material The authors confirm that the data supporting the findings of this study are available within the article. Derived data supporting the findings of this study are available from the corresponding author on request.

Author contribution Chen Dongju:resources and advisory.Wu Shuiyuan: conceptualization, methodology, and writing original draft. He Yazhong, Li Shupei, Luo Yuchi, Wang Xiang: review, editing, and supervision.

Ethical approval All authors confirm that they follow all ethical guidelines.

Consent to participate The authors declare that they consent to participate this paper.

Consent to publish The authors declare that they consent to publish this paper and agrees with the publication.

\section{References}

[1] Cook J . Fracture characteristics of three metals subjected to various strains, strain rates, temperatures and pressures[J]. Engineering Fracture Mechanics, 1985.

[2] Zhou L, Wang Z , Wen H . On the Accuracy of the Johnson-Cook Constitutive Model for Metals[J]. Chinese Journal of High Pressure Physics, 2019.

[3] Sahu S , Mondal D P , Goel M D , et al. Finite element analysis of AA1100 elasto-plastic behaviour using Johnson-Cook model[J]. Materials today: proceedings, 2018, 5(2):5349-5353.

[4] Liu Q F, Wang N C , Yan L, et al. The Dynamic Mechanical Properties of Oxygen Free Copper under the Impact Load[J]. Journal of Mechanical Strength, 2015, 1136(4):543-548.

[5] Xue Q, Nesterenko V F , Meyers M A . Evaluation of the collapsing thick-walled cylinder technique for shear-band spacing[J]. International Journal of Impact Engineering, 2003, 28(3):257280.

[6] Palanisamy P, Rajendran I, Shanmugasundaram S, et al. Prediction of cutting force and temperature rise in the end-milling operation[J]. Proceedings of the Institution of Mechanical Engineers Part B Journal of Engineering Manufacture, 2006, 220(10):1577-1587.

[7] Wang S M , Chiou C H , Cheng Y M. An improved dynamic cutting force model for endmilling process[J]. Journal of Materials Processing Technology, 2004, 148(3):317-327. 
[8] Zhai Y S , Qiao S , Liu X L, et al. The Simulation Analysis and Experimental Research on the Process of PCBN Cutting Super-Alloy[J]. Key Engineering Materials, 2013, 589-590:88-93.

[9] Moufki A , Dudzinski D , Coz G L . Prediction of cutting forces from an analytical model of oblique cutting, application to peripheral milling of Ti-6Al-4V alloy[J]. International Journal of Advanced Manufacturing Technology, 2015, 81(1-4):615-626.

[10] Yang Y, Jin L, Zhu J , et al. Study on Cutting Force,Cutting Temperature and Machining Residual Stress in Precision Turning of Pure Iron with Different Grain Sizes[J]. Chinese Journal of Mechanical Engineering, 33(4):9.

[11] Cai S , Yao B , Feng W, et al. An improved cutting force prediction model in the milling process with a multi-blade face milling cutter based on FEM and NURBS[J]. International Journal of Advanced Manufacturing Technology, 2019, 104(2).

[12] Duan X , Peng F , Zhu Z , et al. Cutting edge element modeling-based cutter-workpiece engagement determination and cutting force prediction in five-axis milling[J]. The International Journal of Advanced Manufacturing Technology, 2019.

[13]Xu, Zhang, Hongbing, et al. Effect of tool angle on cutting force and residual stress in the oblique cutting of TC21 alloy[J]. The International Journal of Advanced Manufacturing Technology, 2018.

[14] Niu Z ， Jiao F ， Cheng K . Investigation on Innovative Dynamic Cutting Force Modelling in Nano milling and Its Experimental Validation[J]. Nanomanufacturing \& Metrology, 2018, 1(2):82-95.

[15] Zhu B , Zhao D , Zhao H, et al. A study on the surface quality and brittle-ductile transition during the elliptical vibration-assisted nanocutting process on monocrystalline silicon via molecular dynamic simulations[J]. RSC Advances, 2017, 7(7):4179-4189.

[16]Houfu, Dai, Hao, et al. Influence of elliptical vibration on the behavior of silicon during nanocutting[J]. International Journal of Advanced Manufacturing Technology, 2019, 102(912):3597-3612.

[17] Chen C , Lai M ， Fang F . Subsurface Deformation Mechanism in Nano-cutting of Gallium Arsenide Using Molecular Dynamics Simulation[J]. Nanoscale Research Letters, 2021, 16(1):1-10. [18] Sharma A , Datta D , Balasubramaniam R . A molecular dynamics simulation of wear mechanism of diamond tool in nanoscale cutting of copper beryllium[J]. The International Journal of Advanced Manufacturing Technology, 2019.

[19] Xu Z , Liu L, He Z, et al. Nanocutting mechanism of 6H-SiC investigated by scanning electron nanoscope online observation and stress-assisted and ion implant-assisted approaches[J]. The International Journal of Advanced Manufacturing Technology, 2020, 106(9-10):3869-3880.

[20] Wang W, Zhang W , Huang D , et al. Cutting force modeling and experimental validation for nano end milling[J]. 2021. 